\title{
Defining stem cell types: understanding the therapeutic potential of ESCs, ASCs, and iPS cells
}

\author{
Clara V Alvarez ${ }^{1}$, Montserrat Garcia-Lavandeira ${ }^{1}$, Maria E R Garcia-Rendueles ${ }^{1}$, \\ Esther Diaz-Rodriguez ${ }^{1}$, Angela R Garcia-Rendueles ${ }^{1}$, Sihara Perez-Romero ${ }^{1}$, \\ Tania Vila Vila', Joana S Rodrigues ${ }^{1}$, Pamela V Lear ${ }^{1,2}$ and Susana B Bravo ${ }^{1}$ \\ ${ }^{1}$ Centro de Investigaciones Medicas e Instituto de Investigaciones Sanitarias (CIMUS-IDIS), Department of Physiology, University of Santiago de Compostela (USC), \\ C/Barcelona S/N, 15782 Santiago de Compostela, Spain \\ ${ }^{2}$ Department of Cardiology, University of Santiago de Compostela (USC) and Hospital Clínico (CHUS), Santiago de Compostela, Spain
}

(Correspondence should be addressed to C V Alvarez; Email: clara.alvarez@usc.es; S B Bravo; Email: susanabelen.bravo@usc.es)

\begin{abstract}
Embryonic, adult, artificially reprogrammed, and cancer...- there are various types of cells associated with stemness. Do they have something fundamental in common? Are we applying a common name to very different entities? In this review, we will revisit the characteristics that define 'pluripotency', the main property of stem cells (SCs). For each main type of physiological (embryonic and adult) or synthetic (induced pluripotent) SCs, markers and functional behavior in vitro and in vivo will be described. We will review the pioneering work that has led to obtaining human SC lines, together with the problems that have arisen, both in a biological context (DNA alterations, heterogeneity, tumors, and immunogenicity) and with regard to ethical concerns. Such problems have led to proposals for new operative procedures for growing human $\mathrm{SC}$ of sufficiently high quality for use as models of disease and in human therapy. Finally, we will review the data from the first clinical trials to use various types of SCs.
\end{abstract}

Journal of Molecular Endocrinology (2012) 49, R89-R111

\section{Introduction}

Stem cells (SCs) are very small cells that do not have the phenotypic characteristics of cells from any known adult tissue (epithelial, connective, muscle, neural, and immune) but are able to generate 'de novo' differentiated cells of the types found in any of these tissues. There are four defined types of SCs: two physiological that are present at different stages of life - embryonic SCs (ESCs) and adult SCs (ASCs) - one engineered or 'induced' (induced pluripotent stem (iPS) cells), and pathological cells present in cancers and having some stem properties (cancer SCs (CSCs)).

Many investigations have been carried out to define the essential characteristics of stemness. Such properties should be common to all known SCs, or at least to cells making up one of the four groups described earlier, and refer to the following functional aspects: 1) expression of markers of pluripotency, 2) activation of signal transduction pathways that maintain stemness, 3) a characteristic proliferative state, 4) how the pluripotent SCs behave in vitro, and (5) how they behave after reintroduction to an in vivo environment.
This review will focus on current knowledge of each different type of normal SC in relation to these five aspects and deals briefly with CSCs. The key concepts elaborated in this review are presented in brief in Table 1.

\section{Embryonic SCs}

ESCs make up the inner cell mass (ICM) of the blastocyst before implantation or before any commitment to embryonic cell fates is detectable at the molecular level. They are the most studied SCs and knowledge obtained from ESCs has guided the investigations of other types of SC.

In vivo, strictly defined ESCs exist only for a short period during development of the pre-implantation embryo, as in parallel with mitotic division, the cells of the embryo become committed and lose their pluripotency (Fig. 1). ESC lines are obtained by enzymatic dispersion of the ICM and culturing under particular conditions. Resulting ESCs possess the capacity not only for infinite self-renewal, in common with other cell lines, but for stably maintaining certain properties 
Table 1 Key concepts

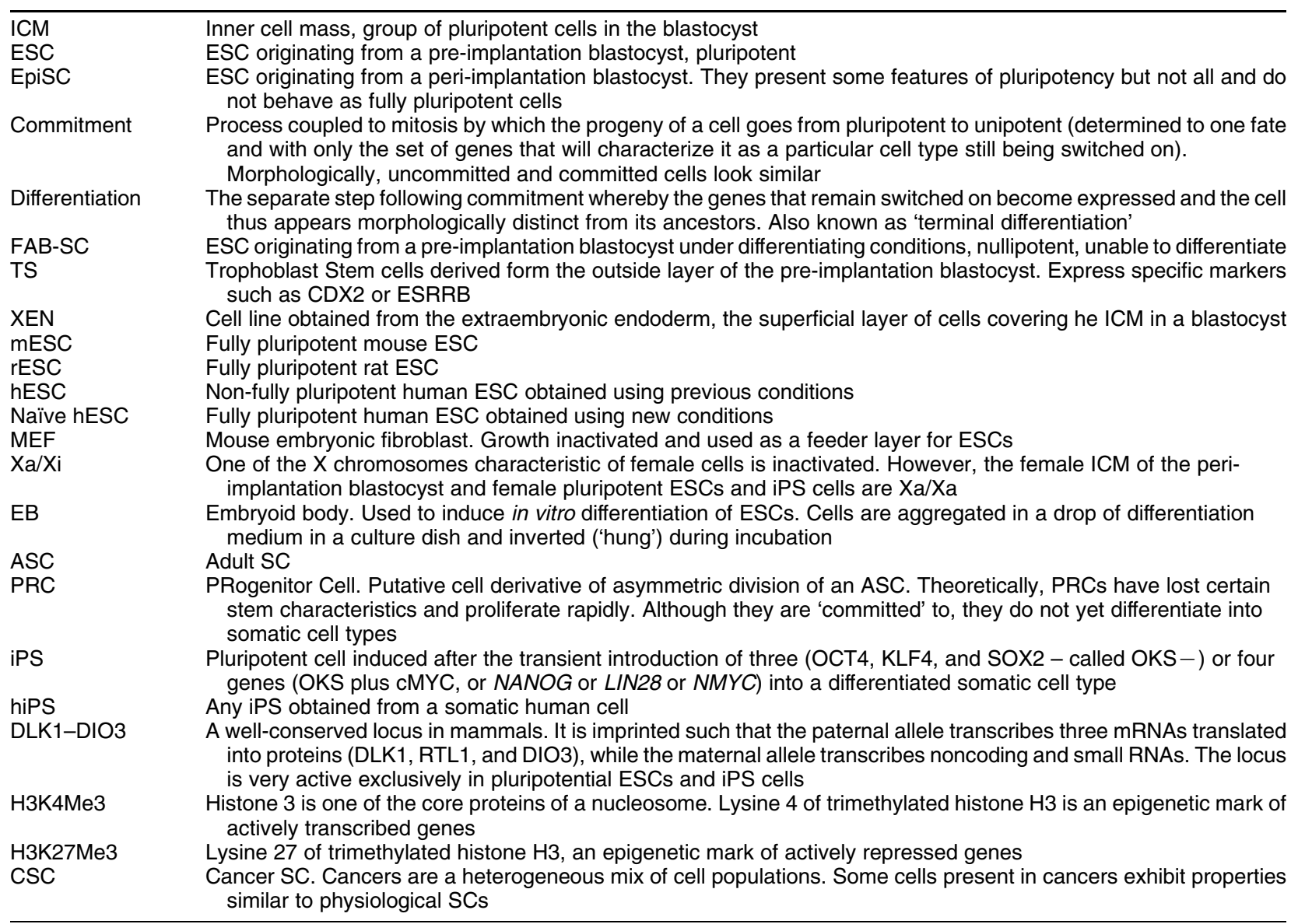

inherent to stemness (see below and Table 2). In recent years, ESC subtypes have been obtained from blastocysts by changing culture conditions. It is, however, now clear that the original parent cells were different. Thus, while fully pluripotent mouse ESCs (mESCs) originate from the epiblast of the pre-implantation ICM, so-called EpiSCs originate from the epiblast of the peri-implantation ICM, and, while maintaining some features of ESCs, are not fully pluripotent. Other unipotent SC lines do not even originate in the epiblast but in the trophoblast (TS) or extraembryonic endoderm (XEN).

During the short period of implantation in the endometrial wall, the mammalian embryo undergoes a huge number of functional genetic changes that are key to its further development (Fig. 1). Epigenetic reprogramming of truly naïve ESCs in the transition from morula to blastocyst is essential for further embryonic development, as shown, for example, in the reactivation of the paternal $X$ chromosome (Blair et al. 2011). X chromosome inactivation (Xi) in females is one of the key events in cells of the female peri-implantation epiblast, leading to their commitment to $\mathrm{Xa} / \mathrm{Xi}$ not only during embryonic development but also in adult life. $\mathrm{Xi}$ is not present in the pre-implantation epiblast whose cells have both the $\mathrm{X}$ chromosomes active $(\mathrm{Xa} / \mathrm{Xa})$. Thus, EpiSCs and mESCs, cell lines obtained in these two different periods, have subtle but important differences.

Other characteristics of pluripotent ESCs are their growth as round compact colonies of very small cells, which is dependent on leukemia inhibitory factor (LIF) but independent of activin/FGF, and resistant to passage by enzymatic dispersion (Pera \& Tam 2010). LIF is a cytokine produced by the endometrium, which allows blastocyst implantation (Stewart et al. 1992). LIF receptor (Gp130) is expressed by ESCs and maintains self-renewal and pluripotency by phosphorylating STAT3 (Williams et al. 1988, Niwa et al. 1998).

The obtainment of ESC lines has been a key historical scientific achievement. In 1981, the first mESC lines were obtained from blastocysts of the Sv129 strain as round colonies on a layer of chemically arrested mouse embryonic fibroblasts (MEFs), known as a 'feeder layer' 


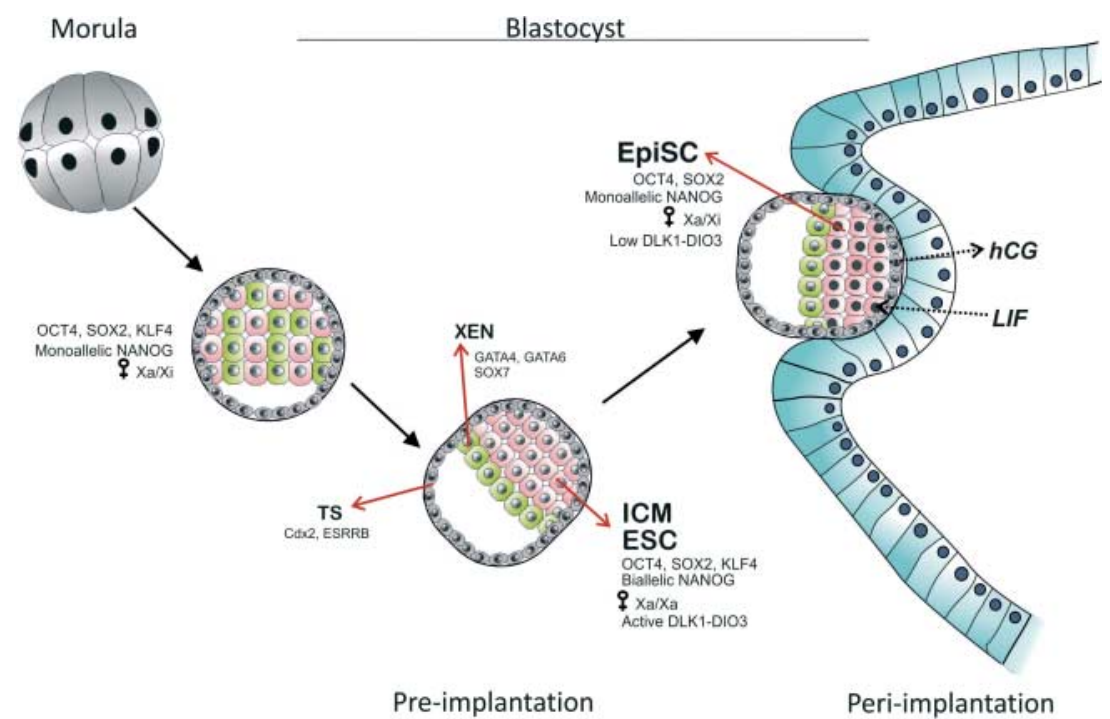

Figure 1 ESCs originate in the ICM of the pre-implantation embryo. Cells presenting all the characteristics of pluripotent SCs, such as expression of the four essential transcription factors (OCT4, SOX2, KLF4, and NANOG), having both X chromosomes active in female cells $(\mathrm{Xa} / \mathrm{Xa})$, and a high activity in the maternal DLK1-DIO3 locus, are exclusive to a compact group of cells ICM inside the pre-implantation blastocyst, and cell lines obtained from them are ESCs. Cell lines have also been obtained from the TS and from the XEN lining the ICM, but these express other markers and are not pluripotent. When the blastocyst starts to implant in the endometrium, molecular events occur such that cells of the ICM and its derivative cell lines (EpiSC) lose their pluripotency.

(Evans \& Kaufman 1981, Martin 1981). Although there was heterogeneity among the resulting colonies, true mESCs were resistant to passage by enzymatic single-cell dispersion and were less easily differentiated than their companions. Other mouse 129 mESCs lines have subsequently been obtained, albeit with technical difficulties. However, mESCs from strains other than 129 and rat ESCs (rESCs) with full pluripotency have continued to be very difficult to isolate.

Owing to such technical difficulties, it took more than 10 years from the initial isolation of mESCs before the first embryonic cell line was obtained from human blastocysts (hESCs) in 1998 (Thomson et al. 1998). A few other ESC lines were obtained during the following years (Reubinoff et al. 2000); until in 2004, a new standardized protocol using FGF + activin (as Nodal) was used to obtain hESCs efficiently (Cowan et al. 2004).

It has, however, become clear that these hESCs are different from mESCs: their morphology is flatter, they are intolerant to passage by enzymatic dispersion and require stimulation of the $\mathrm{FGF} / \mathrm{TGFb} /$ activin pathway for growth, they are easily differentiated into progenitor

Table 2 Mechanisms that maintain pluripotency in ESCs

\section{Expression of genes characteristic of pluripotency}

Codependence of expression of other core transcription factors to maintain correct levels of expression (no more, no less)

Heterodimerization as a regulator of pluripotency genes

Allelic switching

Majority of genes maintained in a poised epigenetic state

Specific repression (overmethylation) of a few specific genes Other epigenetic events
E.g. OCT4, SOX2, KLF4, REX, telomerase, alkaline phosphatase, ABCG2

E.g. indirect regulation of OCT4 expression by SOX2

E.g. OCT4+SOX2 heterodimer allows concurrent binding of the two OCT4 DNA-binding domains

E.g. random transcription from a single allele characteristic of NANOG transcription in non-pluripotent cells. A change from mono- to biallelic expression is exclusive to pluripotent ESCs

E.g. general undermethylation of DNA, histones in promoters sharing features both of activation and repression (H3K4Me3 and $\mathrm{H} 3 \mathrm{~K} 27 \mathrm{Me} 3$ )

E.g. HLA locus, CDKN1B (p27), and RASSF1

E.g. RNA variants generated through alternative splicing or microRNAs 
germ cells, and female cells are chromosome $\mathrm{X}$ inactivated $(\mathrm{Xa} / \mathrm{Xi})$. In fact, such hESCs are quite similar to mouse EpiSCs, obtained from the epiblast of peri-implantation (not pre-implantation) blastocysts and grown in FGF + Nodal but without LIF (see earlier and Fig. 1; Brons et al. 2007, Tesar et al. 2007, Chou et al. 2008, Hanna et al. 2010, Pera \& Tam 2010).

\section{Signal transduction pathways underlying pluripotency}

The technical challenges discussed earlier have led to the ideas of potentially intrinsic species-related differences in pluripotent ESC proliferation (mESCs vs rESCs) and intrinsic instability of pluripotent ESCs (hESCs and mESCs derived from strains other than Sv129). Conversely, it has also been thought that finding the right cell culture conditions will allow ESC lines from any species or strain to be grown and maintained as pluripotent.

Now, after many years of experience with ESC culture, protocols have improved, with reagents being defined precisely and the MEF feeder layer being shown not to be an essential requirement. LIF/STAT3 has been established as the key signal in maintaining ESC pluripotency, while the FGF/MAPK/TGFb/activin pathway has been shown to induce instability and cell commitment and differentiation. So far, the best promoters of pluripotency in the absence of MEF feeders have been LIF $+2 i$, in which LIF is combined with two kinase inhibitors, PD0325901 (a MEK inhibitor) and CHIR99021 (an FGFR/GSK3 inhibitor) (Ying et al. 2008). The medium also contains a mixture of scavengers known as $\mathrm{N} 2+\mathrm{B} 27$ that act as antioxidants and thus resist the high atmospheric concentration of oxygen present in a standard $\mathrm{CO}_{2}$ incubator (about 20\%) relative to the normal internal environment of the blastocyst (around 10\%). Using these LIF $+2 \mathrm{i}$ conditions, pluripotent rESCs and fully pluripotent or 'naïve hESCs' (Xa/Xa, resistant to enzymatic dispersion, stably noncommitted) have now been obtained, demonstrating that it was not an intrinsic species-specific difference but a lack of knowledge that was hindering the maintenance of ESC pluripotency (Buehr et al. 2008, Li et al. 2008, Hirabayashi et al. 2010, Kawamata \& Ochiya 2010).

\section{Markers of pluripotency in ESCs: the balance is in the core}

Much effort has been aimed at identifying the genes that are essential to stemness. Briefly, much of our current information has been obtained using highthroughput technologies and a range of functional in vivo and in vitro systems.
A core group of four first-level transcription factors has been defined. These four factors, OCT4 (POU5F1), SOX2, KLF4, and NANOG, coordinate the expression of the following groups: second-level transcription factors (DPP3 or STELLA, REX1 or ZNF42, and GBX2), cell surface markers (SSEA4 in humans or SSEA1 in rodents), ABC transporters (ABCG2), and certain enzymes (alkaline phosphatase and telomerase TERT) (Pera \& Tam 2010).

Using single-cell RNAseq, Surani's group (Tang et al. 2010) has identified the specific set of genes common to both the epiblast in the pre-implantation blastocyst ICM and to ESCs growing in culture. This set of 'pluripotency' genes is distinct from a set of genes common to the postimplantation ICM carrying out its developmental program and to in vitro ESCs that have been induced to commitment (and thus termed 'loss of pluripotency' or 'induction of differentiation' genes). Genes in the pluripotency set include not only OCT4, NANOG, and SOX2 but also E-cadherin (CDH1), estrogen-related receptor $\beta(E S R R B)$, and certain BMPs, Notch, Frizzled, and DPP4. Genes in the second set include TGFb receptors, FGF and FGF receptors, SOX9, some HOX genes, and VE-cadherin (Tang et al. 2010). An important concept in SC biology is that no core transcription factor should be overexpressed with respect to any of the others: a constant balance maintains the cell in the 'stem state' of pluripotency.

\section{Key mechanisms maintaining pluripotency}

Table 2 shows a summary of the key mechanisms that maintain pluripotency in ESCs.

\section{Codependence}

Once the importance of the balance of expression of core transcription factors was recognized, a derivatory concept was formulated, for which there is now mounting evidence. Thus, regulatory regions of genes expressed by ESCs include close binding sites of the four essential transcription factors, which altogether coordinate gene expression (Chambers \& Tomlinson 2009). When the balance between the core transcription factors is altered, an ESC begins to become committed. For example, in ESCs, an increase in FGF5 but loss of REX1 expression underlies formation of the primitive ectoderm and mesoderm; OCT4 overexpression and/or NANOG repression induces differentiation in the endoderm and mesoderm with loss of potency for an ectodermal fate; SOX2 overexpression induces neuroectoderm differentiation. On the other hand, in ESCs, loss of OCT4 or SOX2 (SOX2 loss also leads to repression of both OCT4 and NANOG) induces formation of XEN. Moreover, ESCs committed to neuroectoderm are rich in SOX2 but 
have lost expression of both OCT4 and REX1 (Niwa et al. 2000, Mitsui et al. 2003, Kopp et al. 2008). Thus, there is a subtle network present in ESCs, in which each of the core transcription factors (such as OCT4 and SOX2) represses their own transcription using classical negative feedback, while at the same time each of the same transcription factors, e.g. SOX2, also induces the expression of the others in a positive feedback, maintaining co-expression.

\section{Heterodimerization}

Another level of regulation resides in the physical protein interactions between pairs of core transcription factors that modulate their effects on gene expression. This has been clearly described for OCT4 and SOX2. OCT4 has two POU DNA binding domains, the POU homeodomain $\left(\mathrm{POU}_{\mathrm{HD}}\right)$ and the $\mathrm{POU}$ specific domain $\left(\mathrm{POU}_{\mathrm{S}}\right)$. On its own, OCT4 is able to bind DNA either through the $\mathrm{POU}_{\mathrm{HD}}$ alone or via both POU domains. However, when bound to SOX2 within a combined OCT4/SOX2 DNA binding site, OCT4 can only bind DNA in the two POU/DNA conformation because part of the SOX2 lateral chains interacts with the POU domain, stabilizing its union with DNA. This has implications for stability and duration of the transcriptional activity of combinations of factors in the regulation of SC genes as it is precisely these genes that have DNA binding sites for OCT4 and SOX2 in close proximity to each other (Kopp et al. 2008, Chambers \& Tomlinson 2009, Ng \& Surani 2011).

\section{Allelic switching}

Recently, a new type of concentration-dependent regulation known as 'allelic switching' has been described for NANOG expression in the mouse embryo. It is well known that the concentration of NANOG is directly related to pluripotency (Chambers et al. 2003), while a reduction of NANOG by half in heterozygous ES $+/$ - cells induces their commitment (Hatano et al. 2005, Hough et al. 2006). Interestingly, morula cells transcribe NANOG from a single random allele, which thus expresses only half the dose of NANOG. Once in the blastocyst, ICM cells with a preimplantation epiblast fate express NANOG biallelically at the dose usually necessary for full pluripotency (Miyanari \& Torres-Padilla 2012). With further commitment in the peri-implantation epiblast, monoallelic expression returns. Similar bi- to mono-allelic regulation occurs in vitro with pluripotent ESCs, compared with those that are induced to commitment. Strikingly, when only one allele is transcribed, either allele can be the one to be transcribed, showing that there is active 'allelic switching' rather than a permanently repressed allele. It is not known how this switching is achieved, nor if it occurs in any other core transcription factor, nor whether such mono-/bi-allelic regulation of human NANOG is conserved in hESCs. However, epigenetic mechanisms appear to have been excluded.

\section{Poised promoters}

Epigenetics have also been compared between ESCs and committed cells in relation to chromatin modifications and DNA structure. DNA as a whole is substantially undermethylated $(3 \%)$ in ESCs compared with differentiated cells $(60 \%)$. In spite of this generally unmethylated state, some genes are characteristically repressed (over-methylated) in ESCs compared with differentiated cells, for example, CDKN1B (p27), RASSF1, and genes of the HLA locus. Other genes are actively transcribed (undermethylated) in ESC, e.g. FGFR3 and TGFBR1. In the postimplantation embryo, an essential de novo demethylation occurs in parallel with the developmental differentiation program (Bibikova et al. 2008, Rada-Iglesias et al. 2011).

At the level of chromatin structure, a similar global histone undermethylation is seen in ESCs (4 vs $10 \%$ in differentiated cells). But the fuller picture is not as simple. ESC promoters, for example, present histone $\mathrm{H} 3$ trimethylated in the lysine 4 (H3K4Me3), characteristic of actively transcribed promoters, and also $\mathrm{H} 3$ trimethylated in the lysine 27 (H3K27Me3), which is characteristically a repressive chromatin marker. At its simplest, this can be interpreted as the majority of the genes not being actively transcribed but still 'poised' or bivalently prepared for binding, either by enhancing or repressing transcription factors. During the differentiation program, loss of pluripotency induces a gradual loss of this dual K4/K27 chromatin marker and a corresponding gain in both sole $\mathrm{K} 4$ (active) and sole K27 (repressed) genes (Guenther et al. 2010).

\section{Other epigenetic mechanisms}

Other epigenetic mechanisms such as alternative splicing are also regulated in pluripotency. Notable differences in transcriptional variants and microRNAs are present in pluripotent ESCs and pre-implantation ICM epiblast compared with non-pluripotent ESCs or the developing ICM (Ng \& Surani 2011).

The most studied epigenetically regulated locus in SCs is the Dlk1-Dio3 locus. In the ICM and in ESCs (as well as iPS cells - see below), this is a precisely imprinted but very active locus. The locus is located on chromosome 12 in mice and chromosome 14 in humans but imprinting is well conserved. The paternally inherited allele expresses three mRNA/protein coding genes (DLK1, RTL1, and DIO3) while the maternally inherited allele expresses various noncoding 
large and small RNAs that repress the polycomb PRC2 complex (da Rocha et al. 2008). ESCs (and iPS cells) that lose pluripotency show significantly reduced activity of this locus, diminishing expression of the noncoding RNAs from the maternal allele (Liu et al. 2010, Carey et al. 2011, Bilic \& Izpisua Belmonte 2012).

\section{Functional assays for ESCs that define pluripotency in vitro and in vivo}

A combination of in vitro and in vivo techniques has been used to demonstrate pluripotency in SCs. In vitro, ESC lines grow as round colonies of very small cells expressing pluripotent markers (NANOG, SOX2, OCT4, and KLF4) and showing activity for the two enzymes telomerase and alkaline phosphatase. As detailed earlier, a feeder layer of arrested cells is not essential, while optimal growth is obtained with serum and LIF $+2 \mathrm{i}$ medium. The size and the roundness of the colonies are two characteristics defining the degree of pluripotency, while flatness of the colony is seen as indicating a first step toward commitment and differentiation.

When injected into a mouse, ESCs cause formation of teratomas, tumors with differentiated structures arising from any of the three primitive embryonic layers (ectoderm, mesoderm, and endoderm). The efficiency can vary depending on the site of injection (dorsal s.c., intratesticular, or i.m.). It is important to note that not only fully pluripotent mESCs generate teratomas as EpiSCs (activin + FGF dependent and derived from the peri-implantation epiblast, see earlier) and non-naïve hESCs (grown in activin + FGF) also form teratomas. However, mouse FAB-SCs, arising from the pre-implantation epiblast but in the presence of FGF2, are nullipotent and unable to give rise to teratomas.

The essential in vivo criterion of pluripotency is the ability to generate chimeric mice. A chimera is obtained after injecting about 10-20 ESCs into a normal blastocyst with the derivatives of the injected cells appearing in all organs of the neonate, including the germ cells. Only truly pluripotent mESCs or rESCs are able to integrate into the blastocyst and participate in the development of chimeric animals (Buehr et al. 2008, Pera \& Tam 2010). EpiSCs and FAB-SCs are unable to generate chimeras, demonstrating that they are not fully pluripotent.

In vitro pluripotent $\mathrm{mESCs}$ are able to differentiate when grown as an embryoid body (EB), a structure derived from ESCs when cultured for more than 14 days as very compact cellular aggregates in floating conditions ('hanging' in a drop of medium cultured upside down in a dish). EBs lose expression of pluripotent genes and gain differentiation genes (FGF5, TGFb, tubulin $\beta$ III, nestin, and others). EBs are useful as an in vitro model of the initial steps of implantation as primitive endoderm, visceral endoderm, and ectoderm are obtained from mESCs. Commitment toward neuroectoderm or endoderm can be achieved using selected growth factors in the incubation medium during EB formation. Changes in gene expression or epigenetic events can therefore be closely monitored (Niwa \& Fujimori 2010). A novel protocol to obtain pituitary Rathke's pouch primordia from EB has been recently published (Suga et al. 2011).

Alternatively, mESCs can be induced in vitro to become committed to a range of somatic cell fates through the use of modified media and dish coatings. Protocols are based on the successive addition of growth factors and hormones together with serum or particular conditioned media for long periods (10-15 days). Commitment is an active process in the ESC that requires gene activation and epigenetic chromatin modifications, such as an increase in H3K4Me3 (Jiang et al. 2011). In general, however, efficiency is low. Differentiated cells should be growth arrested and express the spectrum of markers corresponding to the somatic cell type. Most importantly, they should show functionality (secretion, response to normal feedback mechanisms, and depolarization under the right conditions).

The search for appropriate combinations of additive cocktails, coatings, and incubation times to achieve effective and efficient cell differentiation is one of the most active areas within the ESC field. In fact, much of this research is patented (see 'Clinical Trials' below). While there are several protocols described for ESC differentiation, only a few include in vivo experiments in which the cells achieve normal somatic cell functionality and tumor generation is studied.

One of the first studies to achieve these goals obtained insulin-secreting $\beta$ cells from mESCs - albeit with low efficiency and little short-term functionality in vivo (Soria et al. 2000, Lumelsky et al. 2001). mESCs have also been converted into a variety of neuronal cell types, but not without the worst side effect of malignant tumor formation at the site of injection. Tumor occurrence has been inversely related to the degree of commitment of the cells before injection (Bjorklund et al. 2002, Erdo et al. 2003). Protocols have now been improved to the point of being able to direct differentiation toward specific glial (see 'Clinical Trials' below) or neuronal subtypes that maintain functionality when injected into the chicken spinal cord (Peljto et al. 2010).

As ESCs proliferate rapidly, they might become a major source for SC therapy in patients with organ failure, in which broad-spectrum regeneration is needed. As an example, it is estimated that effectively replacing a diabetic endocrine pancreas requires one million islets; this is the equivalent of about two billion functionally active $\beta$ cells that are more easily obtained 
than islets (Holland et al. 2009). However, a low differentiation efficiency would reduce the rate of success and potentially increase unwanted side effects from using ESCs.

In summary, ESCs are derived from pre-implantation epiblasts and maintain pluripotency using a core group of transcription factors that are themselves regulated by mechanisms such as codependent expression, co-binding to promoters, and allelic switch regulation, as well as epigenetic events such as undermethylation of DNA or chromatin fingerprinting of poised promoters (Table 2). ESCs lines grow very fast. Much current research is aimed at growing ESC lines while maintaining cell pluripotency. At the same time, efficient commitment and differentiation protocols will be key to the clinical application of ESCs to human therapeutics.

\section{Adult SCs}

ASCs are postnatal derivatives of ESCs located throughout the body. ASCs maintain co-expression of at least three of the four transcription factors characteristic of ESCs (OCT4, KLF4, and SOX2) and show high expression of $\mathrm{ABC}$ transporters and alkaline phosphatase. It is not clear whether they spontaneously express telomerase. In common with ESCs, but unlike differentiated somatic cells, ASCs overexpress intermediate filament proteins (E-cadherin and vimentin) and $\beta$-catenin (bCat) (http://www.ebi.ac.uk/gxa/). Additionally, every organ-specific ASC expresses a set of characteristic markers. Similar to ESCs, it is not the overt expression of a single factor but the presence of a balanced network among a core of stem markers that maintains ASC characteristics.

\section{To express or not to express: stemness as an all-or-nothing category}

ASCs have been described in many different organs, but it is not yet known how many markers are common to all ASCs or which are organ specific. One area of debate is whether populations of ASCs each expressing different sets of genes may coexist in the same organ. Some ASC markers are also expressed by differentiated somatic cells, although with different levels of expression, and not in a coordinated manner with respect to core stem factors. As an illustration of the complexity of our current understanding, we will discuss nestin and CD133.

Nestin is an intermediate filament protein. Intermediate filaments comprise a family of over 50 genes divided into six groups (I-VI) according to sequence homology. Nestin belongs to group VI. Intermediate filaments are responsible for supporting the weight of the cell nucleus and distributing mechanical stress through multiple connections with the plasma membrane and to neighboring cells or the extracellular matrix. Such plasma membrane junctions resist tensions generated by the stretching of cells making up each tissue, and in response each cell adapts its intermediate filaments to its particular shape and size. Thus, the expression of one or other intermediate filament type can be said to define the cell type. Nestin was originally discovered in the rat spinal cord. It is expressed by neural precursors and by both glia and neurons during embryonic development. In adults, neural SCs and their nonterminally differentiated derivatives continue to express nestin. Nestin is, however, expressed during embryonic development by many other cell progenitors including non-ectodermal pancreatic and muscle precursors. Moreover, in adults, nestin-positive cells have been found in the same locations as ASCs. It is currently believed that nestin is the quintessential marker of mesenchymal SCs (MSCs), one of the principal types of ASC (Mendez-Ferrer $\mathrm{et}$ al. 2008). In the CNS, nestin is also believed to be associated with cells 'activated to proliferate' (stem, progenitor, or activated cells in neural tissue under repair; Gilyarov 2008).

CD133 (prominin 1, product of the PROM1 gene) is a transmembrane protein essential for retinal development. Mutations in this gene give rise to macular degeneration in the human eye. CD133 is expressed not only by ASCs but also by photoreceptors and many adult epithelial and glial cells, in which it is localized to the plasma membrane of cellular protrusions. Thus, in polarized cells, it is seen in the microvilli of the apical side, and in many cell types, it is associated with the membrane of the primary cilium, an immotile sensory cilium present in all cells (Karbanova et al. 2008).

In common with nestin, CD133, and many other genes, such as the $\mathrm{ABC}$ transporters (ABCG2), what characterizes an ASC is not the expression of any one marker at high levels but the coordinated expression of a set of markers including a core of pluripotency transcription factors that together define the precise type of SC. Just as for ESCs, future studies of ASCs need to focus on sets of markers.

\section{The ASC niche: MSCs and parenchymal SCs}

ASCs can be divided into so-called 'parenchymal' - generating new somatic nonconnective tissues - and MSCs, which generate new somatic connective tissue cells such as fibroblasts, adipocytes, chondrocytes, osteoblasts, smooth muscle cells, and probably skeletal muscle satellite cells. MSCs have been characterized by many markers depending on their location. Among these, expression of CD271 with or without CD146 
has been described in bone marrow MSCs and CD29 and CD105 in subcutaneous and peritoneal fat MSCs (Zapata 2012).

While MSCs are extensively distributed, parenchymal ASCs aggregate in the organs in a structure called the niche. In this niche, ASCs are maintained in quiescence or at a low basal rate of division, while being protected, nurtured, and supported by MSCs (Fig. 2). The niche does not exist during embryonic development when most if not all cells are proliferating intensively while at the same time becoming committed. The niche receives a specific neural sympathetic (e.g. adrenergic in bone marrow) and vascular (CD31 or PECAM+) supply. When the blood in these capillaries becomes depleted of oxygen, Wnt ligands are released inducing a response that mobilizes ASCs through bCat activation (see below).

Niche MSCs express nestin and secrete factors that regulate proliferation, retention, or mobilization of ASCs. In the bone marrow niche, MSCs also express $\beta$ adrenergic receptor 3 , angiopoietin 1 , and the chemokine CXCL12, while hematopoietic SCs (HSCs) express CXCR4, one of the CXCL12 receptors. Circadian adrenergic activity drives recruitment of HSCs from the niche by reducing expression of the cytokine CXCL12 by MSCs (Katayama et al. 2006, Lucas et al. 2008, Mendez-Ferrer et al. 2008, 2010), and this is the first demonstration of the CNS regulating a peripheral niche via the peripheral nervous system. Interestingly, G-GSF, a factor widely used in bone marrow transplantation, also activates recruitment and mobilization of HSCs toward the peripheral blood supply by sympathetic activation.

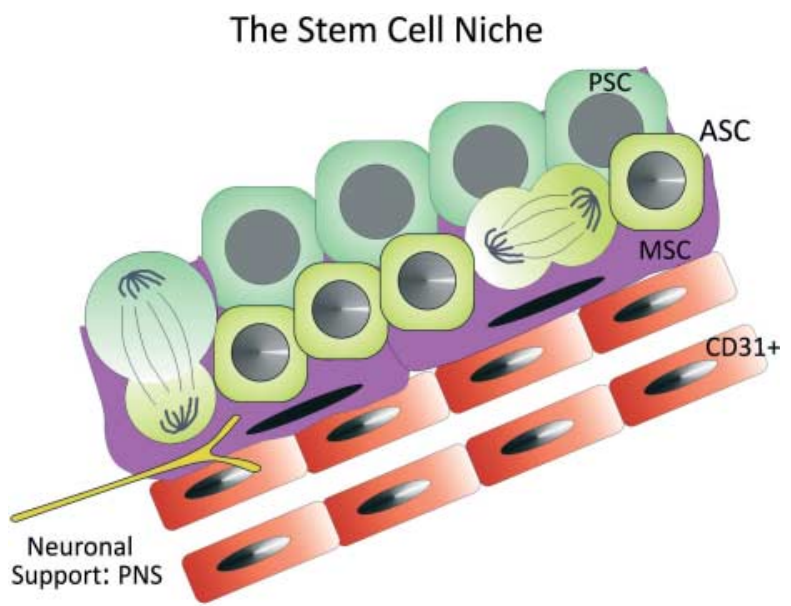

Figure 2 The adult SC niche. ASCs are organized in a compact structure supported by MSCs and receiving specific nervous (sympathetic) and vascular support. ASCs maintain a basal slow proliferative rate that neutrally drives the cells either to remain in the niche or become converted into progenitors and leave the niche. Randomly occurring factors such as proximity to cytokines might decide ASC fate through symmetric or asymmetric divisions.
ASCs are much more difficult to study than ESCs, as physiologically they are maintained in a nearly arrested or slowly proliferating state in the organs. Attempts to grow ASCs in vitro require them to divide, which is contrary to their most intrinsic feature of quiescence. The current prevailing view is that in vivo ASCs eventually enter into symmetric division at a constant but very slow rate (Cheshier et al. 1999, Snippert et al. 2010).

A very interesting regulatory mechanism in the mouse skin niche has recently been proposed, whereby SCs are transiently activated when each new cycle commences in a hair follicle. ASCs generate progenitors that leave the niche, proliferate, and slowly differentiate to produce a new hair. However, a few committed progenitors migrate back to the niche, situating themselves near the SCs. In the presence of the returned cells, the resident SCs are resistant to activation, as though their threshold had been increased (Hsu et al. 2011). This is similar to the classical 'negative feedback' mechanism described in endocrinology and mediated by hormones and other factors, but in the ASC niche, it would appear to be effected out by the cells themselves.

\section{Markers of ASCs: common to all or tissue specific?}

Table 3 summarizes markers described to date for ASCs characteristic of each organ.

\section{Symmetric or asymmetric division?}

To date, the prevalent model of steady-state niche regulation has been the 'hierarchical model', in which the number of ASCs in the niche is maintained through symmetric division - one mother ASC gives rise to two daughter ASCs. When recruited for activation, an ASC enters into asymmetric division, giving rise to one daughter ASC and one daughter progenitor cell (PRC). Although the molecular mechanisms underlying the transition to PRC are not fully understood for every niche, the trigger is thought to be a subtle alteration in the balance of ASC markers. PRCs actively proliferate and maintain expression of some SC markers but are restricted in pluripotency. After proliferation, PRCs ultimately differentiate into somatic cells. It is assumed that the number of divisions of a PRC before it becomes determined varies between organs and/or tissues. For example, in bone marrow, it is high but in endocrine organs it would be low.

A mechanism associated with the hierarchical model is that of asymmetric divisions in the niche presenting nonrandom DNA strand segregation. This so-called 'immortal hypothesis' postulates that in ASCs, DNA synthesis produces an 'immortal' strand. The original 
Table 3 ASC markers

Hematopoietic stem cells (HSCs)

Mesenchymal stem cells (MSCs)

Muscle stem cells (MuSCs)

Small intestine stem cells

Liver and pancreas stem cell

Testes: progenitor germ cells (PGCs)

Skin stem cells (bulge)

Neural stem cells (NSCs)

Lung stem cells (LuSCs)

Cardiac stem cells (CaSCs)

Pituitary stem cells (GPSs)
$0.005 \%$ of BM CD150+/CKIT+/SCA1+/CD244-neg/CD48-neg/LIN-neg/nestin-neg

Less pluripotent progenitors: CD150-neg/CD244+/CD48-neg

Committed progenitors: CD150-neg/CD244-neg/CD48+ (Kiel et al. 2005)

Nestin +, CD271 +/CD146 and CD146+, CD29, CD105

Some markers differ according to tissue of origin

Can be located either individually or as the non-parenchymal part of the ASC niche

(Zapata 2012)

Previously known as satellite cells

Stemness: PAX3+/PAX7+ and microRNA-489+ (Dek receptor downregulation)

Myocyte committed progenitors: MyoD +/Myf5+/Myostatin + and Dek + (Rando

2005, Relaix et al. 2005, Cheung et al. 2012)

LGR5 + high/SOX2 + high/SOX9+low

$\mathrm{BMI}+$ other stem population or different functional state of the same stem population?

Committed enteroendocrine precursors: SOX9+high (Barker et al. 2007, Sangiorgi \&

Capecchi 2008, Formeister et al. 2009)

A common stem cell for both organs under discussion

Differentiated hepatocytes have capacity for self-renewal

Liver stem cell: SOX9+

Pancreas stem cell: exocrine, ductal, and endocrine populations proposed. Also, a common ductal ASC for all tissues has been proposed

Other hypotheses do not involve stem cells but self-renewal of committed precursors, e.g. NGN3+-islet-specific precursors (Xu et al. 2008, Burke \& Tosh 2012)

RET +/GFRA1 +/PLZ +/ETV5+/BCL6B +/NANOG-neg

and OCT4low/SOX2very low/SOX9low (Alvarez CV et al. unpublished)

Sertoli cells: SOX9+-high (Meng et al. 2000, Costoya et al. 2004, Lee et al. 2007,

Oatley et al. 2007)

LGR5 +/SOX9+/TCF3+ (and others; Blanpain et al. 2004, Tumbar et al. 2004, Claudinot et al. 2005, Fuchs \& Horsley 2011)

Niches in the subgranular zone of the dentate gyrus of the hippocampus, the subventricular area of the lateral ventricles, the olfactory bulb, and the spinal cord

No consensus as to what layer within the niche constitutes the real NSC

Radial glia-like cells: SOX2+/MSH1 +/BLBP + are the most probable candidates in vivo and in vitro (Ellis et al. 2004, Merkle et al. 2007, Suh et al. 2007, Kriegstein \& Alvarez-Buylla 2009, Bonaguidi et al. 2011)

Many candidates proposed (p63+-basal airways cells, alveolar type II pneumocytes, Clara cells) with repair properties after injury but expressing differentiation markers

A new population proposed in humans cKIT +/SOX2+/OCT4+/KLF4+/NANOG + with in vivo and in vitro stem properties (Rock et al. 2009, Anversa et al. 2011, Kajstura et al. 2011)

Initial descriptions of HSC recruitment to infarction sites started a debate about putative in situ CaSC

Fused HSC cardiomyocytes have limited capacity for self-renewal

Niches of CKIT + described in human heart with in vivo and in vitro CaSC properties (Bearzi et al. 2007, D'Amario et al. 2011)

GFRA2 +/GFRA3+/RET+/PROP +/SOX2 +/OCT4+/KLF4+/SOX9+/PROP +/ECadherin-high/bCat high

Nestin-negative

Under discussion which is the most stem cell population: SOX $2+/ \mathrm{SOX} 9+$ or SOX $2+$ /SOX9 - (Fauquier et al. 2008, Chen et al. 2009, Garcia-Lavandeira et al. 2009, 2010, 2012, Castinetti et al. 2011) strand is always segregated to the daughter ASC and serves as a template, while the daughter PRC always receives the newly copied strand. Such a mechanism could ensure stability of the DNA sequence, thus preventing mutations. This hypothesis has, however, been recently challenged by evidence using multi-isotope mass spectrometry coupled with microscopy to detect nucleotide-labeled DNA. Rather than supporting the 'immortal strand' hypothesis, the data show DNA strand segregation in SCs to be random (Steinhauser et al. 2012).
A new 'stochastic model' has also been recently proposed to explain renewal in the SC niche. This new model is a product of studies in several niches, the HSC, the skin, the testis, and the small intestine, using in vivo labeling of single clones of dividing SCs (Clayton et al. 2007, Kiel et al. 2007, Klein et al. 2010). In one study, intestinal crypt SCs were labeled using random recombination of fluorescent proteins, a so-called rainbow cassette. After specific induction of Cre recombinase in the SCs, singly dividing SCs were irreversibly marked in one of four different colors. 
Following the labeled cells for several weeks showed a progression to monoclonal labeling of a whole villus, including both its stem and derivative somatic cells (Snippert et al. 2010). These results suggest that there is a stochastic or unpredictable loss of some SCs, which become converted into somatic cells and are replaced in the niche by dividing neighbors. This model therefore predicts a slow but continuous symmetric division of SCs, which fortuitously generates either two ASCs, two PRCs, or one ASC and one PRC. Such SCs would follow 'neutral drift' dynamics toward differentiation. Local constraints such as competition for niche space, proximity to cytokines, ligands, or MSCs could determine which cells retain stemness and which become progenitors and ultimately somatic cells.

\section{Functional assays for ASCs that define pluripotency in vitro and in vivo}

After purification, ASCs can be grown in vitro in the absence of serum but the presence of selected growth factors (LIF), as well as other additives such as N2 and B27, a mix of micronutrients and antioxidants, and hormones such as retinoids, insulin, progesterone, tri-iodothyronine $\left(\mathrm{T}_{3}\right)$, and corticosterone, all at supposedly physiological concentrations. In these conditions, ASCs grow as rounded cell spheres, sometimes even as hollow spheres called spheroids. These spheres/ spheroids express similar SC markers to those expressed in the niche in vivo and are negative for somatic markers. Functional assays for alkaline phosphatase activity in vitro are positive in pluripotent ASCs only and negative in PRCs. Labeling the cells of the spheres with BrdU demonstrates active proliferation. These spheres can be passaged a few times, although they are very sensitive to trypsin as they grow in the absence of serum.

When the spheres are attached to the dish after addition of serum, differentiation can be induced using an appropriate cocktail of hormones and other factors. It is time-consuming to optimize conditions for each type of ASC, such that in spheres they maintain pluripotency but subsequently they can become differentiated efficiently into every somatic cell type normally present in their organ of origin. Protocols for differentiation usually combine successive addition of growth factors and hormones over several days. In general, efficiency of differentiation is quite low and appears to be random. One of the first described protocols was conversion of pancreatic SCs into insulinproducing $\beta$ cells (Ramiya et al. 2000), while several others have now been described.

Although generating sufficient number of ASCs by in vitro amplification can be problematic, labeling, and reinjecting ASCs in vivo has been informative once enough cells are obtained. Injection sites include the organ of origin and a model site such as under the renal capsule, where ASCs survive and differentiate. In either case, ASCs tend to reconstruct the architecture of their organ of origin. Injection of human ASCs (hASCs) into immunodepressed mice or rats (immunocompromised strains or treated with cyclosporine) has demonstrated their capacity to generate the full range of different somatic cell types present in their organ of origin and has thus been considered to show pluripotency in hASCs (Bearzi et al. 2007, Anversa et al. 2011, D'Amario et al. 2011).

In summary, ASCs are more difficult to study than ESCs, and, accordingly, we have less knowledge of their physiology. Although we still lack evidence for several niches, it seems plausible that ASCs will have a balanced set of markers in common, such as SOX2, OCT4, KLF4, LGR5, SOX9, and perhaps cKIT or NANOG. It is also clear that ASCs express specific markers depending on niche location. Current consensus is that the life of ASCs in the niche follows a stochastic model of slow basal proliferation and neutral drift toward commitment and differentiation.

\section{Induced pluripotent SCs}

The cellular plasticity hypothesis proposes that just as a pluripotent cell becomes committed and differentiates into a somatic cell, it can also be converted back into a SC. Many experiments have been performed to try to demonstrate this ability to 'turn back'.

\section{Somatic cell nuclear transfer}

The first technique developed was somatic cell nuclear transfer (SCNT). The nucleus of a differentiated somatic cell is introduced into an enucleated oocyte, which retains in the cytoplasm all the tools necessary for reprogramming the nucleus. After stimulation, the composite cell is transformed into an ESC, which undergoes embryonic development. Some cloned animals were obtained in this way, starting famously with 'Dolly' the sheep (Wilmut et al. 1997). SCNT aims to produce large quantities of SCs, sufficient for effective cell therapy, and using the nucleus from one of the patient's own cells to avoid the problem of autoimmunity.

However, SCNT has significant theoretical and methodological weaknesses as well as a lack of underlying molecular biological knowledge. First, in the reprogrammed cell, mitochondria are always derived from the oocyte. Secondly, the process is very inefficient, suggesting that the reprogrammed somatic chromatin is subjected to high stress. Thirdly, the molecular epigenetic pathways underlying this reprogramming are largely unknown, making it hard either to optimize the method or to ameliorate unwanted side 
effects such as premature aging in the resulting organism. Indeed, to date, there have been no ESC lines generated using this technique. One line that had been thought to be generated had to be retracted after it was shown to have originated by parthenogenesis of the recipient oocyte rather than by reprogramming of the somatic nucleus, using a methodology now considered not have adequate controls (Hwang et al. 2005, Kennedy 2006, DeWitt 2007).

Although scientifically considered to be very difficult, SCNT has also raised fears of human cloning in the future and is therefore subject to serious legal constraints. Several groups continue to work with SCNT, due to its potential to resolve simultaneously three fundamental problems in cell therapy: obtaining enough cells (embryonic cells proliferate more rapidly), immunotolerance (the somatic nucleus comes from the patient), and ethical concerns about harvesting embryos (an oocyte is more acceptable).

\section{Reprogramming}

The second strategy in somatic cell reprogramming has been transfection with candidate genes. In a famous report by Takahashi and Yamanaka 2006, expression of a combination of four genes, OCT4, KLF4, SOX2, and $c M Y C$, was sufficient to reprogram mouse skin fibroblasts and obtain iPS cells (Takahashi \& Yamanaka 2006). Subsequently, cMyc was omitted as its contribution was found to comprise only accelerating proliferation. Human iPS (hiPS) cells were obtained immediately after using LIN28 as the fourth gene (Takahashi et al. 2007, Yu et al. 2007).

To generate a fully pluripotential mouse iPS cell line able to generate chimeric mice, another gene, NANOG, has also been shown to be essential. iPS cells thus obtained have been combined with a donor normal blastocyst and the mice born have cells of both origins in their organs (Okita et al. 2007). Fully reprogrammed mice have also been obtained using 'tetraploid complementation', in which iPS cells are injected into an altered blastocyst derived from cell fusion at the twocell stage. Tetraploid blastocysts are unable to develop into embryos but can form extraembryonic tissues. The obtainment of embryos after injection of iPS cells into a tetraploid blastocyst therefore demonstrates that iPS cells are as pluripotent as ESCs (Ohi et al. 2011).

One drawback of this methodology is that integration and expression of the four genes necessary to initiate reprogramming is not always stable using viral infection in somatic cells. Techniques such as transient plasmid expression and even transit protein delivery have successfully achieved reprogramming and active iPS cell division (Okita et al. 2008, Zhou et al. 2009). However, such nonintegrative techniques are inefficient at generating iPS cells.
There have also been extensive efforts to elucidate the molecular events underlying reprogramming. These have revealed, first, that an essential requirement is the expression and activity of telomerase (Marion et al. 2009a). Secondly, we now know that all somatic cells have a p53 'Rubicon' that normally prevents differentiation from being reversed. Reprogramming needs to cross this molecular impasse by getting rid of p53 (Hong et al. 2009, Marion et al. 2009b). Based on this latter finding, a third method of obtaining iPS cells has recently been proposed. Using an animal episomal vector that does not integrate with DNA but remains stably replicating within the nucleus, the method also downregulates p53 by means of a p53shRNA and increases efficiency with LIN28 and NMyc (avoiding unwanted side effects of cMYC; Okita et al. 2011).

\section{Instability of iPS cells: intrinsic or technically soluble?}

At the same time as generating such a wealth of functional data, the first signs that iPS cells are not as untransformed as first postulated have begun to appear. In Yamanaka's initial 2007 report of chimeric mice obtained after iPS cell injection, 20\% of the offspring developed tumors (Okita et al. 2007). This was attributed to a side effect of cMyc. However, while protocols have now replaced cMyc with $\mathrm{NMyc}$, it appears that the underlying cause could be that rapidly dividing iPS cells are not very accurate about stably maintaining their DNA.

hiPS cells have been compared with naïve hESCs both in terms of gene expression and epigenetic chromatin structure (poised promoters: methylations in lysine 4 and 27 of histone H3). Importantly, no differences have been found with truly pluripotential iPS cells (Guenther et al. 2010). However, it seems that reprogramming is not an all-or-nothing situation, and some properties of the original somatic cell remain in at least some hiPS clones (Ohi et al. 2011). Using high-throughput sequencing, a high DNA variability has been seen in hiPS cells obtained from a single somatic cell (Bock et al. 2011). Moreover, hiPS cells have shown mutations that can be either inherited from the somatic cell or arise de novo, as well as some chromosomal aneuploidies or alterations in gene copy-number variations, including increased copies of oncogenes and deletions in tumor suppressors (Gore et al. 2011, Peterson et al. 2011). In addition, hiPS cells have generated epigenetic alterations de novo during the reprogramming process that are characteristic of cancer cells $(\mathrm{Ohm}$ et al. 2010).

Together, these findings have led to a call for quality control in the generation of iPS cells (Blasco et al. 2011). Most experts warn that reprogramming generates a diverse range of iPS cells and recommend selecting only the cell that best matches all criteria after reprogramming. Cloning and amplifying a single 
'truly pluripotent' iPS cell should reduce heterogeneity and even prevent the unwanted side effects of using altered cells for therapy.

A battery of tests are therefore currently being standardized, in order to distinguish 'the good' iPS cells from the 'altered' ones. Similar to ESCs (see earlier), the DLK1-DIO3 locus is imprinted in iPS cells. Pluripotent naïve iPS cells also maintain the high activity of this locus producing many noncoding RNAs from the maternal allele, whereas altered iPS cells show reduced expression. The status of this locus is therefore one of the validation tests to be passed for any iPS cell to be used in human therapy (Liu et al. 2010, Carey et al. 2011, Bilic \& Izpisua Belmonte 2012). Other tests include expression of cell surface markers or alkaline phosphatase (see below, Baker (2012)).

\section{iPS cells as models of disease}

There are also several advantages to using hiPS cells. First, they have already been obtained from every human somatic tissue. Secondly, hiPS cells have been obtained from patients affected by incurable diseases, providing an in vitro model in which to study these diseases and to test drugs. In monogenetic diseases, pathologic hiPS cells can be submitted to gene therapy and re-differentiation for future use in cell therapy. Among the first diseases studied were QT syndrome (mutation of the potassium channel KCNQ1), Leopard syndrome (mutation of the PTPN11 gene encoding SHP2 phosphatase), and the genomic imprinting disorders Angelman syndrome (loss of $U B E 3 A$ gene) and Prader-Willis syndrome (of unknown origin) (Chamberlain et al. 2010, Moretti et al. 2010). Subsequently, hiPS cells from other diseases have also been isolated.

In summary, iPS cells constitute a great achievement as they demonstrate that we understand animal cell biology well enough that, with the appropriate tools, we can reverse what previously seemed to be an irreversible process, that of somatic cell differentiation. The further study of hiPS cells will improve our understanding of several diseases and lead to the development of therapies. However, the reprogramming process itself alters many cells, limiting its use. Future studies will probably be aimed at the use of new generation 'haute couture' artificial nucleases, either zinc-finger ZNF or TALE nucleases (see below), to replace very precisely the diseased gene with a gene in optimal condition without alteration of other chromatin sites (Hockemeyer et al. 2009, 2011).

\section{A brief note on CSCs}

Cells with functional properties and markers similar to physiological SCs have been found among the broad cell spectrum in solid cancers and leukemias. Such cells are resistant to many therapies due to their small size, slow rate of division, and high expression of $\mathrm{ABC}$ transporters, as well as expression of telomerase and key SC genes (e.g. SOX2) but not differentiation markers. Cells with these characteristics are considered true CSCs.

The initial and attractive hypothesis was that CSCs were altered/mutated ASCs, or SCs that had become cancerous. However, little evidence has been found to support that idea. Conceptually, too, a slow rate of division in ASCs is thought to preclude the accumulation of mutations that give rise to CSCs. Today, CSCs are viewed as those cancer cells that have adopted the most beneficial properties of SCs (small size, slower rate of proliferation, and markers) and have additionally downregulated p53 and generated their own niche, which protects them from the rest of the internal environment (Borovski et al. 2011). As a result, CSCs are resistant to insults such as chemotherapy and radiation that normally kill other rapidly proliferating tumor cells. The description of each tissue- and tumor-specific CSC is far beyond the scope of this review.

\section{Role of bCat in SCs, commitment, and differentiation}

bCat is a well conserved gene (CTNNB1), driving the expression of an intracellular protein with two very different proposed functions, one as a transcription factor and the other in cell adhesion. Human bCat protein homology is $99 \%$ with the mouse (Mus musculus), $97 \%$ with zebrafish (Danio rerio), and $67 \%$ with the fruit fly (Drosophila melanogaster) (http://www.ncbi.nlm. nih.gov/homologene/1434). bCat contains 12 units of the ARM domain, a domain first described in the armadillo homolog from flies. This domain is implicated in cytoplasmic protein-protein interactions.

bCat is expressed in many somatic cell types and highly in epithelial cells. Importantly, both ESCs and ASCs have a much higher level of expression than any differentiated cell. The two functions described for bCat are sometimes attributed to its origin from two different intracellular pools. The first pool of bCat is located just on the cytoplasmic side of the plasma membrane. Here, bCat forms an important part of the adherens junctions, together with intermediate filaments (mainly E-cadherin in ESCs and ASCs), and the actin filaments of the cell cortex. The second pool of bCat is cytoplasmic and continuously degraded. When its N-terminal part (Ser33) is phosphorylated by kinases such as GSK3b bound to the complex APC/AXIN, bCat becomes ubiquitinated and degraded. Phosphorylation by other kinases in different residues, including serines and threonines as well as tyrosines, leads to stabilization 
and nuclear localization of bCat. Wnt ligands promote this pathway by inhibition of the GSK3/APC/AXIN complex, preventing bCat N-terminus phosphorylation and degradation. Mutations of bCat N-terminal serines/threonines, or inactivating mutations in GSK3b or APCs, lead to nuclear accumulation of bCat, which is related to tumor formation.

In the nucleus, bCat interacts with transcription factors. The most studied bCat interactors are the TCF/LEF family, which are also activated by Wnt. bCat/TCF dimers activate transcription in genes presenting TCF response elements (e.g. Brachyury, Axin, or Cdx1). There are also other transcriptional partners that can form complexes with nuclear bCat to activate or repress transcription. bCat seems to participate actively in the differentiation of committed progenitors and somatic cells. In such cells, bCat binds to tissue-specific transcription factors, e.g. SOX17 in endoderm formation, SOX1 in neural commitment, SF1 and DAX1 (NROB1) in adrenal and gonadal differentiation, PITX2 and PROP1 in pituitary development, and PAX3 in melanocyte commitment (Human protein reference Database, www.hprd.org; Olson et al. 2006, Kim et al. 2008).

bCat submembrane signaling through adherens junctions seems to be essential during embryonic development for the normal formation of epithelia in organs such as the airways, intestines, and skin. In its role in cell-cell adhesion, bCat is not acting as a nuclear transcription factor, but in positioning cells within the epithelial layer. It allows transient disruptions of the epithelium during cell division and growth and then returns the cells to their previous positions within the laver.

The role of bCat in SCs is not yet clear. In ESCs and ASCs, bCat has two apparently opposing roles: selfrenewal and maintenance of pluripotency but also induction of commitment and differentiation. Wnt ligands induce a strong bCat nuclear transcriptional activity. As Wnt expression is strongly associated with embryonic development and cell pluripotency, it seems highly likely that nuclear bCat is also important in the maintenance of SC properties. Within the nucleus, bCat needs another transcription factor as a partner to bind DNA. It has been proposed that, rather than the transcription factor itself, it is the nuclear coactivator/ corepressor that associates with bCat and is the key factor determining which of the two opposite roles of bCat becomes activated. In this model, bCat would promote pluripotency and symmetric cell division, upregulating genes such as OCT4 and survivin, but only when associated with the coactivator CBP (CREB binding protein or CREBBP). bCat associated with p300, however, would promote asymmetric cell division and commitment through CDX2 or EPHB2 (Miyabayashi et al. 2007).
bCat activation is regulated by oxygen concentrations in SCs. When hypoxia $\left(1.5 \% \mathrm{O}_{2}\right)$ is sensed in the stem environment, Wnt-induced Hifla activates the transcription of TCF/LEF that binds bCat and activates transcription. This pathway is conserved in ESCs and ASCs. These data reinforce the greater importance of the nuclear over the cytoplasmic action of bCat in SCs (Mazumdar et al. 2010).

Recently, however, this view has been challenged, at least for ESCs. A bCat-deficient ESC line showed no apparent difference in self-renewal compared with WT ESCs (Lyashenko et al. 2011). However, bCatnegative ESCs had altered adhesion and were unable to form neuroectoderm, mesoderm, or endoderm. Differentiation was rescued by transfection of mutant bCat, which had conserved cytoplasmic cell adhesion function but was unable to migrate to the nucleus.

As mentioned earlier, the kinase GSK3 induces bCat degradation. Although bCat is not essential, in its absence, ESC self-renewal is decreased due to loss of pluripotency markers such as OCT4, KLF4, and alkaline phosphatase. As a GSK3 inhibitor (CHIR99021) is currently used to culture ESCs (LIF + 2i conditions), the role of bCat in self-renewal of ESC lines is being studied. Two new mechanisms of action for nuclear bCat independent of TCF transcription have been proposed. The first is based on the finding that in bCatnegative ESCs, there is enhanced expression and overactivation of the $T C F 3$ transcription factor. As $T C F 3$ is a strong repressor of pluripotency genes, this alters the co-regulating network of stemness and induces commitment and differentiation. As intracellular bCat sequesters TCF3 from nuclear binding sites, it prevents the repressive actions of TCF3 on the core group of pluripotency transcription factors. Therefore, it is proposed that ESCs require a GSK3 inhibitor in order to maintain a pool of cytoplasmic bCat and thus pluripotency (Wray et al. 2011). Another novel transcriptional mechanism for bCat, involving OCT4, has been proposed after studying ESCs in the absence of GSK3b and with point mutant-active cytoplasmic bCat (C-terminal deletion). Such cells are unable to differentiate and have high intracellular bCat levels as well as enhanced levels of pluripotency factors. It is therefore proposed that bCat binds OCT4, potentiating its transcriptional activity and enhancing pluripotency (Kelly et al. 2011). It is not yet known whether these two new roles of nuclear bCat independent of TCF transcriptional binding sites might also exist in ASCs.

ASCs resident in the niche, however, show a strong sub-membrane bCat expression. This can be seen in the pituitary niche (Fig. 3; Garcia-Lavandeira et al. 2009, 2010, 2012) and suggests that strong adherens junctions are an essential part of a lifelong niche that has resident ASCs. If ASCs are recruited, bCat expression would transiently become nuclear. This has been 

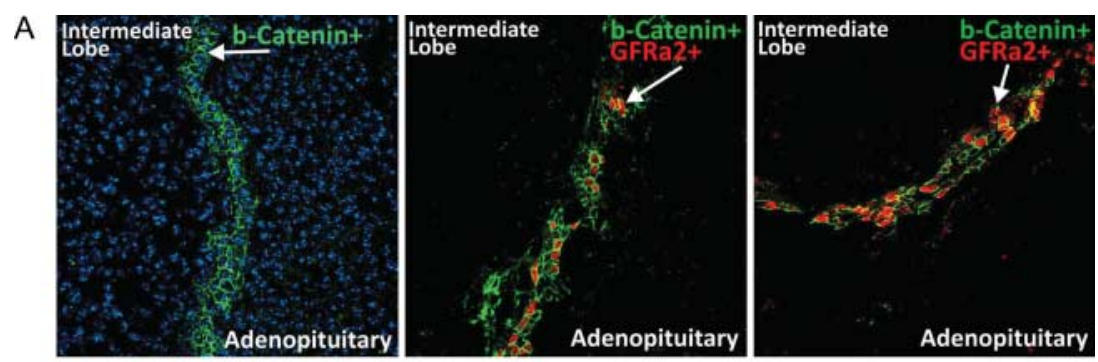

B
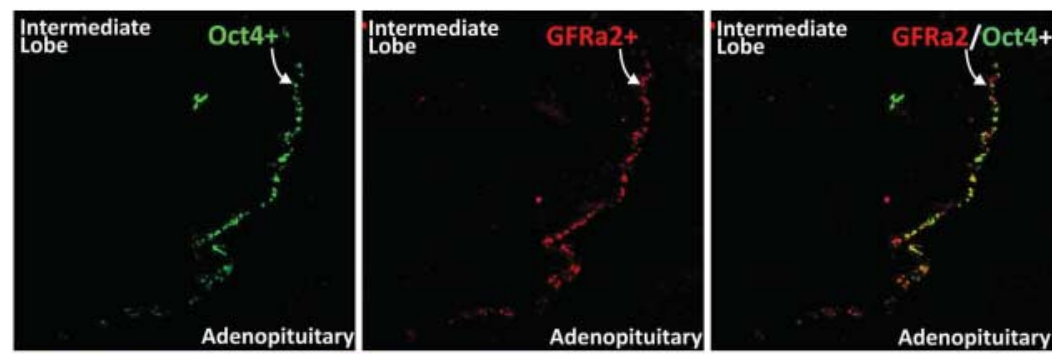

C

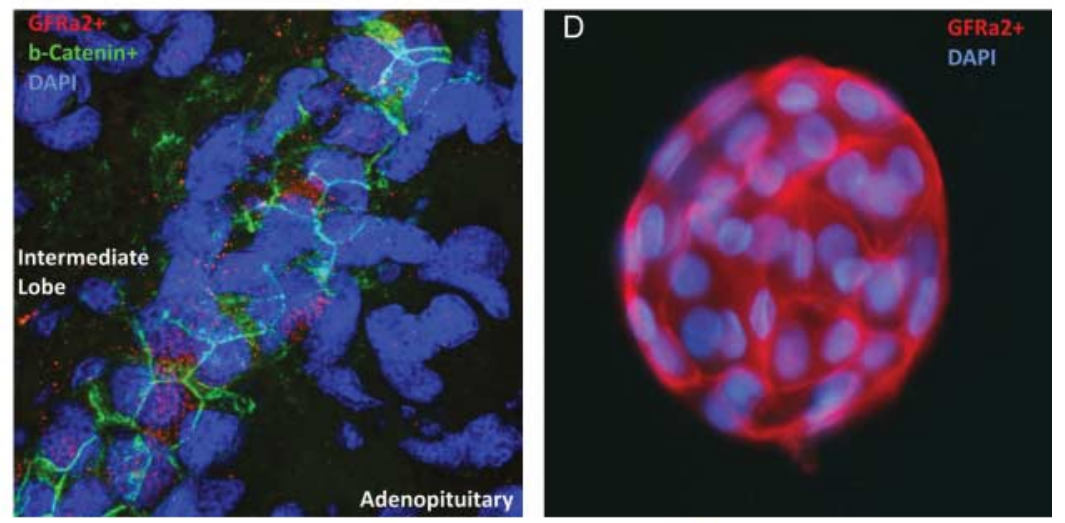

E
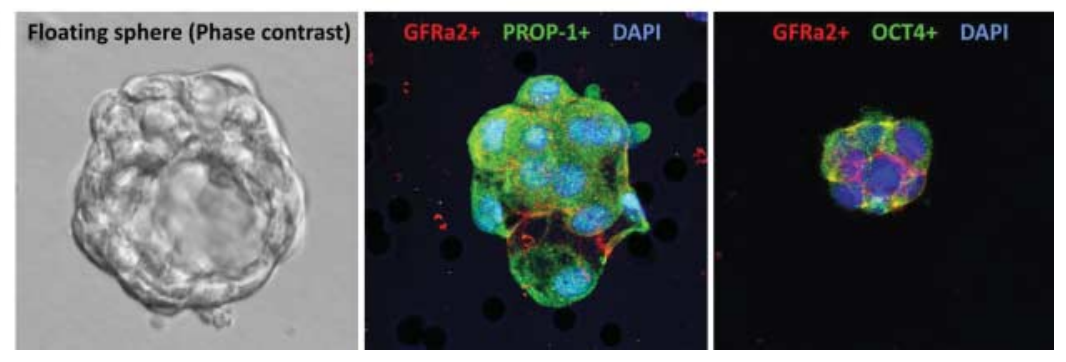

Figure 3 The adult pituitary SC niche. ASCs in the pituitary are aligned in a compact manner at the border between the anterior and intermediate lobes. They co-express bCat and factors of the GFRa/RET family (A), Prop1 and SC factors (B), and are therefore known as GPS. Cells are strongly attached by cytokeratins and bCat (C). When purified using the cell surface marker GFRa2 and grown in the absence of serum, these ASCs form spheres that maintain expression of the membrane receptor GFRa2 and transcription factors such as Prop1 or Oct4 (D and E).

partially demonstrated in the pituitary where activating bCat mutations driven under the promoter of the pituitary progenitor transcription factor Hes 1 give rise to craniopharyngiomas (Gaston-Massuet et al. 2011).

Taken as a whole, this work suggests that bCAT can have different functions in SCs than in differentiated cells. The next challenge will be to determine whether bCat has a common role in all types of SC or specific roles in ESCs, ASCs, committed progenitors, differentiated somatic cells, and mutated cancer cells. Of key importance to understanding bCat's mechanisms of actions will be the elucidation of when and where its cell adhesion function (and association with cadherins) takes precedence over its nuclear 
transcription function and with which transcription factor (TFC, OCT4, or tissue specific), repressor (TCF3), or coactivator (CBP or p300) it interacts in any given situation (Fig. 4).

\section{Future perspectives}

This last section will focus on a few aspects related to all types of SCs that are anticipated to be important in the near future.

\section{Basic science: aging SCs}

Many triggers for cellular aging have been proposed, among them, the intracellular accumulation of old or altered biomolecules such as lipids and proteins make it impossible for the cell to maintain its normal rhythm of

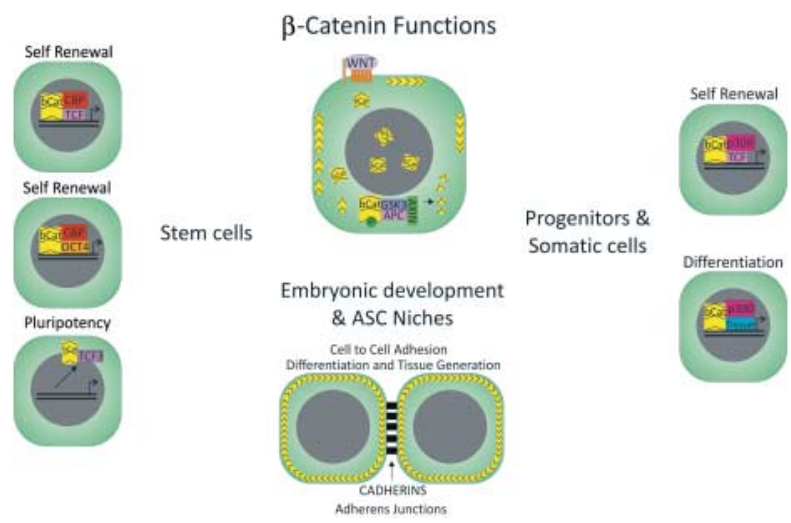

Figure 4 The proposed roles of bCat. bCat is associated with intermediate filaments on the cytosolic side of the plasma membrane. bCat released into the cytoplasm is sequestered by the AXIN/APC complex and phosphorylated by GSK3. This leads to bCat degradation by proteosomes. Some extracellular factors (e.g. Wnt) prevent regulatory bCat phosphorylation, thus allowing its migration to the nucleus. Nuclear bCat regulates gene expression as part of a complex with other transcription factors. In ESCs, the bCat complex formed with activating members of the family TCF/SRF (e.g. TCF2) activates cell division. In ESCs, bCat also binds OCT4 to maintain cell renewal. A different mechanism is proposed for maintenance of pluripotency. Nuclear bCat binds the repressing member TCF3, preventing its binding to DNA and maintaining expression of SC genes. During embryonic development, bCat plays a major role at the plasma membrane through adherens junctions and in combination with cadherins. Wnt factors can also regulate sub-membrane bCat through alternative noncanonical pathways. Postnatally, resident ASCs within the niches show a high expression of sub-membrane bCat. Nuclear bCat induces somatic cell commitment and differentiation by binding to specific differentiation factors such as Sox2, Sox17, SF1, Pitx2, or Prop1. In progenitor/somatic cells, bCat maintains selfrenewal by binding to TCF. It seems that there are different nuclear coactivators/corepressors for the bCat-TCF complex in ESCs than in progenitor/somatic cells, potentially explaining its different actions. CBP is present in ESCs while p300 is present in progenitor/somatic cells. biosynthesis. While such proteotoxicity and lipotoxicity seem a plausible explanation for nondividing neurons, for dividing cells, there must be also some form of 'replicative aging'. The most widely held view is that every time a cell divides, it is more likely to pass on accumulated DNA mutations and adverse epigenetic events to its descendants, which in turn have the potential for increasingly compromised function. As SCs are the only cells that divide throughout life, it is therefore likely that they are the main cells to age and that their aging will have tissue and organism level aging consequences (Liu \& Rando 2011). In relation to this, it has been proposed that fetal microchimerism, namely the crossing of fetal SCs to the mother during pregnancy, is a source of rejuvenation of the mother SC pools (O'Donoghue 2006, Galofre \& Davis 2007). In an attractive hypothesis, this phenomenon would increase the ability in women to repair tissues and organs and thus contribute to their greater longevity. However, this has yet to be demonstrated and a neutral and/or pathogenic role for fetal microchimerism has also been proposed (Klonisch \& Drouin 2009, Fugazzola et al. 2011).

Some very recent experiments not only show that the loss of proliferation associated with ageing of neural SCs is reversible but also suggest that it could be mediated by the endocrine system. Rando and colleagues have studied neural SCs (NSCs) in the subgranular niche of the dentate gyrus of the hippocampus, using parabiotic mice of two different ages and paired for 1 month (young-old, young-young, and old-old) (Rando 2005). In heterochronic pairs, several interesting data were obtained (Villeda et al. 2011). First, an increase in proliferating NSCs was found in the old mouse, whereas the young mouse showed a decrease compared with control levels; isochronic pairs showed no such changes, and glia were unchanged in all cases. Intriguingly, the NSC changes were associated with functional alterations in memory, with faster long-term potentiation and higher memory test scores in the older paired mice with increased NSC proliferation but the opposite for the younger mice. As blood was the only shared tissue, the experiments were repeated using injections of plasma instead of parabiosis; similar results were obtained. Finally, a plasma-borne cytokine CCL11 was found to be increased in older mice and injection of this cytokine into young mice partially reproducing the NSC arrest and memory alterations. If such findings can be reproduced in other niches, it will be feasible to hypothesize that the endocrine system plays an important role in aging.

\section{Translational science: how can sufficient numbers of safe and stable SCs be obtained and used therapeutically?}

SC therapy requires a source of hundreds of millions of SCs per patient. As ASCs are difficult to grow and are 
not unequivocally pluripotent, ESCs were initially the best candidate source. ESCs, however, have two serious problems - biologically, they have tumorigenic potential, being highly proliferative and adaptable to different environments, while ethically they are derived from an embryo (albeit at the very early blastocyst stage). While the latter is not always viewed as problematic by the patient, the emergence of iPS cells has brought substantial new hope of making SC therapy safer.

The discovery of genetic, epigenetic, and genomic alterations in reprogrammed iPS cells (as described in the previous sections) has led to a fundamental rethinking of in vitro strategies to maintain iPS cells in a proliferating but stable state (Blasco et al. 2011), and several new procedures to improve efficiency of iPS cell culture are being developed (Saha et al. 2011). One intriguing recent discovery in the mouse has been the importance of the stoichiometry of reprogramming factors for the stability of iPS cells. Thus, if the reprogramming protocol includes twice the amount of OCT4 and KLF4 compared with SOX2 and cMYC, the resulting iPS cells are genetic and epigenetically stable and fully pluripotent. Importantly, the 'reprogrammed' mice generated from these iPS cells do not develop tumors, in contrast to those derived using the original protocol with 1:1:1:1 stoichiometry (Carey et al. 2011).

Using mRNA profiling, karyotyping, or wholegenome sequencing, good-quality iPS cells are readily distinguished. A new and very active current focus is the development of live-cell staining to detect unaltered but fully reprogrammed iPS cells, worthy of amplification and study, from the plethora of colonies. The technique must not perturb cell viability (as do labeling with antiTra1-60 antibodies and in vivo alkaline phosphatase staining; Baker 2012). Others propose to gather hiPS cells in registered banks for submission to a stringent set of tests of 'terminal differentiation' and to validate for human use only those that pass the tests (Boulting et al. 2011).

New strategies to reprogram somatic fibroblasts directly into the differentiated cell type required by an individual patient are also being tested, in order to obviate the need for iPS cells and subsequent redifferentiation. In a recent report, a combination of six reprogramming factors was able to directly convert mouse fibroblasts into dopaminergic neurons. In vivo, these artificial neurons were integrated in the brain and had functionality (Kim et al. 2011). There is also excitement surrounding the potential application of zincfinger-tailored ZNF and TALE nucleases, which can replace altered genes within the genome of a patient's iPS cells (Hockemeyer et al. 2009, 2011). Chosen as the 'Method of 2011' by Nature Methods, this individually tailored approach makes gene therapy seem less a dream and more a reality (McMahon $e t$ al. 2011).

\section{Clinical aspects: immunity, tolerance, and graft rejection}

In 2002, the encouraging discovery that ASCs appeared to be immunotolerant was made. Mouse cardiac progenitor cells expressing GFP were injected into rats and directly observed in the weeks following their incorporation into the myocardium (Saito et al. 2002). Mouse iPS cells and ESCs, by contrast, have been found to be immunogenic, generating T-cellmediated immunity and tissue damage after injection into an allogenic mouse strain. Worse still, iPS cells reprogrammed with viral or episome vectors have also elicited an immune response when introduced into their own syngenic strains, due to the residual foreign proteins they express following the reprogramming process. ESCs, at least, have been found not to be immunogenic when introduced into a syngenic strain (Zhao et al. 2011).

MSCs are well known for their acute anti-inflammatory properties in vivo, both in syngenic animal models and after autotransplantation in humans. They are recruited to the inflammatory area and seem to exert their beneficial effect by reducing proliferation and activation of cytotoxic T, B, and natural killer cells as well as antigen-presenting cells such as dendritic cells and macrophages. MSCs, moreover, induce regulatory T-cells that modulate the immune response (Corcione et al. 2006, English et al. 2008, Spaggiari et al. 2008, Uccelli et al. 2008, Ghannam et al. 2010). Some MSC anti-inflammatory properties are known to be mediated by cell-cell contact-induced pathways (Duffy et al. 2011). Owing to their immunomodulatory properties, MSCs have been proposed as a therapeutic agent in autoimmune and host-vs-graft disease. However, few clinical trials, addressing either autologous or allogeneic MSCs, or with sufficient numbers of patients, have been conducted (Zapata 2012).

Recently, however, the concept of MSC immunomodulation has been challenged. In adult rats, MSCs injected into allogenic animals were clearly immunogenic, causing T-cells to release IFNg and TNF that destroyed the MSCs (Liu et al. 2011, Schu et al. 2012). If validated in other systems, these data could leave ASCs as the only SC type that induces allogenic immunotolerance. Taken together, therefore, the data seem to indicate that when using MSC or ESC derivatives, only autotranplants will be safe. Clearly, the immunogenicity/tolerance properties of each different type of SC will need to be elucidated before SCs can be considered for widespread application in cell therapy requiring allogenic sources of cells. In the meantime, other benefits that should be considered include recruitment of the patient's own MSCs to inflammatory sites as a potential therapy in cancer (see below). 


\section{Clinical trials using cell therapy}

Many of the early studies using autologous SC injections in patients did not have adequate controls or were not double-blinded. The current scenario is very different, with about 3400 controlled clinical trials registered as 'Cell Therapy' in the NIH database (http://clinicaltrials.gov/). Of these, nearly 1900 have now finished, although only some 125 have presented their results. Many of these clinical studies are phase I trials relating to safety issues and many use autologous bone marrowpurified populations. A few hundred are using MSCs, although none has yet formally presented their results; some trials are using skin derivatives grown in vitro. Currently, $<50$ trials are endocrinology related, of which all are using cell therapy in diabetic patients but none have yet presented their results.

Success of cell therapy in patients need not necessarily be directly due to cell regeneration from the injected SCs but instead to reduction of cell damage or improvement of tissue repair by indirect mechanisms. These could include control of inflammation, immunosuppression, secretion of growth factors, and increased cell survival. Recently, in rats and other animal models, partial locomotor recovery after spinal damage has been obtained through multiple mechanisms after SC injections (Sakai et al. 2012). In models of stroke, similar functional recovery has been achieved after injection of MSCs into the carotid artery or intravenously, although substantially fewer cells incorporated into damaged brain issue via the i.v. route (Gutierrez-Fernandez et al. 2011).

Here, we will list some of the ongoing trials, starting with those that use ASC populations and finishing with those using ESCs. The phase I double-blinded SCIPIO trial (NCT00474461) investigates injection of autologous cKIT + CaSCs into the heart of a small group of ischemic cardiomyopathy patients. While there seem to be some improvements in cardiac function, the number of patients is low and it is too soon to predict ultimate usefulness for this particular cell therapy (Bolli et al. 2011). In spinal cord and CNS diseases, a call has been made for careful human clinical trials detailing short-term vs long-term evaluations of the patient (Snyder \& Teng 2012). In spinal cord injury, the NCT01321333 phase I trial is studying purified NSCs (HuCNS-SC), while NCT01490242 is using autologous bone marrow MSCs. In amyotrophic lateral sclerosis, the NCT01348451 trial uses spinally derived SCs and NCT01494480 uses fetal umbilical cord-derived MSCs. A different approach is used by NCT01151124, where a proprietary Myc-ER viral immortalized neural SC line is being used to improve sequelae in stroke patients. There are three ongoing phase I trials using ESCs, differentiated into either retinal pigmented cells, for treating Stargardt's Macular
Dystrophy (NCT01469832) and age-related macular degeneration (NCT01344993), or oligodendrocytes for treatment of traumatic spinal cord lesion (NCT01217008, GRNOPC). However, the abrupt closure of the Geron biotechnology company - said to be due to economical rather than scientific reasons - has suddenly attenuated the high expectations that GRNOPC ESC derivatives had raised. The trial will remain active with respect to following up patients already injected.

Concerns about safety in all these trials have increased since early reports of donor-derived leukemia after bone marrow transplants and one case of multiple neural tumors in the spinal cauda equina and brainstem meninges arising 5 years after repeated transplantation of fetal neural precursors (Greaves 2006, Amariglio et al. 2009). It has therefore been proposed that cells used in therapy should have an inherent trigger for destruction if necessary, and a modified inactive caspase 9 transgene has recently been introduced into human T-cells. This protein is fused to an FK protein domain and needs access to a smallmolecule drug to dimerize and become active, inducing apoptosis. The modified T-cells have been injected into five leukemia patients who previously received a matched isotypic bone marrow transplant and have been detected and found to be functionally active in peripheral blood. Indeed, when four of these patients developed graft-vs-host disease, as expected in many transplant patients, a single injection of the dimerizing drug was enough to control the disease and prevent its recurrence (Di Stasi et al. 2011).

It will be challenging to integrate cell therapy into routine hospital procedures. An example of this has been seen recently in a simple clinical trial using MSCs to treat perianal fistulas that are resistant to other forms of treatment. The initial study with a small group of patients in a single hospital was very promising (Garcia-Olmo et al. 2005). However, in the phase II study (NCT00999115), significant variability in outcome has been seen; this has been attributed to the enrollment of surgeons from several hospitals who each injected the cells (prepared in a single lead hospital) in a slightly different manner. It is important to remember that biological therapy is dynamic and multi-faceted, and not following the exact procedure for any one aspect, such as handling cell vials, can lead to significant variation in results (Garcia-Olmo, personal communication).

Finally, cell therapies are not applicable exclusively to regeneration but can also be useful in cancer. A recent study used an oncolytic virus, an adenovirus bearing mutated oncogenes that specifically arrests and kills cancer cells, to transduce autologous MSCs, which were then injected into four children with grade IV neuroblastoma resistant to therapy. MSCs were recruited and migrated into the tumor. In one of the 
young patients, the virus destroyed enough tumor cells to generate a CD8 cytotoxic response, the tumor disappeared and the patient was free of the disease (Garcia-Castro et al. 2010). Improving oncolytic viruses and adjusting the doses of injected MSCs could therefore have potential as be an alternative therapy in some advanced cancers in the future.

\section{Ethical and legal aspects of SCs: efficiency, safety, and patents}

The use of SCs raises ethical concerns for two principal reasons: the source of the ESCs is an embryo and necessitates its destruction and pluripotent SCs (ESCs and iPS cells) might be used to clone human beings. Both reasons have been discussed at length with a mixture of religious, political, and scientific arguments. It is therefore understandable that moral and ethical principles have guided the design of specific legislation in this topic.

Under the general directives of the European Community (EC), each country has its own laws, leading to a degree of uncertainty within the international scientific community as to the detailed procedures that may or may not be carried out in any particular collaborative project. Legislation affects not only clinical and basic research but also specifically SC-related biotechnology. In November 2011, the full Chamber of the European Court of Justice agreed on the interpretation of Directive 98/44/EC, establishing the non-patentability of ESC derivatives used in applications outside the embryo (Case-law of the Court of Justice-JUDGMENT OF THE COURT (Grand Chamber). 18 October $2011(*))$ and therefore of direct relevance to ESC lines used for research and ultimately cell therapy. This decision has led to a heated debate between scientists, industries, patients, and lawyers, each of whom are economically affected by the decision. It therefore remains to be seen whether the decision will slow investigation or simply change the way in which the results of SC research are legally registered.

As a guide for both patients and scientists, the EC runs the EuroStemCell internet site, which gathers information about ethical concerns, research projects, and clinical trials (http://www.eurostemcell.org/factsheet/embyronic-stem-cell-research-ethical-dilemma). The International Society for Stem Cell Research (ISSCR) has a specific section on ethical issues and guidelines for the clinical application of SCs (http://www.isscr.org/Ethics_and_Stem_Cells/2911. htm). In the USA, the National Academies and NIH also have specific websites with guidelines for research using SCs and to address patients' concerns (http://www.nap.edu/catalog.php?record_id = 11278; http://stemcells.nih.gov/info/ethics.asp).

However, while basic and clinical research has been regulated and is strictly monitored, the use of autologous cell injections of more or less purified populations of HSCs or MSCs in patients in private clinics is not controlled. Not only have such treatments not been subjected to a double-blinded clinical trial but they are unlikely to be as it is considered unprofessional to charge the patient for something s/he does not individually receive. The current explosion in private SC therapy is a source of worry to scientists owing to the ineffectiveness and potential danger of treatment with untested therapies and, furthermore, the negative effect on public opinion of SC research in general that an adverse outcome would inevitably cause (Cyranoski 2012).

To conclude, we are in a new era of SC therapy in which its true efficacy will be tested. It will still be many years before we can accurately evaluate the results of SC therapies already carried out and assess which therapy is most appropriate or how it should be further adapted for any particular disease. But it can clearly be seen that considerable progress is being made toward understanding the potential of several types of SC, both biologically and therapeutically.

\section{Declaration of interest}

The authors declare that there is no conflict of interest that could be perceived as prejudicing the impartiality of the review reported.

\section{Funding}

This work has been supported by grants Xunta de Galicia-MICINNFEDER, 06PXIB208107PR, 09CSA011208PR, BFU2007-60571, and BFU2010-16652 to C V A and by the Spanish Network of Collaborative Cardiological Research (REDINSCOR) funds to P V L. M G-L is a recipient of an Isabel Barreto technological grant. E D-R has been an Anxeles Alvariño fellow (Xunta de Galicia). This program is cofinanced by the European Community (Fondo Social Europeo, FEDER).

\section{References}

Amariglio N, Hirshberg A, Scheithauer BW, Cohen Y, Loewenthal R, Trakhtenbrot L, Paz N, Koren-Michowitz M, Waldman D, Leider-Trejo L et al. 2009 Donor-derived brain tumor following neural stem cell transplantation in an ataxia telangiectasia patient. PLoS Medicine 6 e1000029. (doi:10.1371/journal.pmed.1000029)

Anversa P, Kajstura J, Leri A \& Loscalzo J 2011 Tissue-specific adult stem cells in the human lung. Nature Medicine 17 1038-1039. (doi:10.1038/nm.2463)

Baker M 2012 Reprogramming: faithful reporters. Nature Methods $\mathbf{9}$ 231-234. (doi:10.1038/nmeth.1899)

Barker N, van Es JH, Kuipers J, Kujala P, van den Born M, Cozijnsen M, Haegebarth A, Korving J, Begthel H, Peters PJ et al. 2007 Identification of stem cells in small intestine and colon by marker gene Lgr5. Nature 449 1003-1007. (doi:10.1038/nature06196) 
Bearzi C, Rota M, Hosoda T, Tillmanns J, Nascimbene A, De Angelis A, Yasuzawa-Amano S, Trofimova I, Siggins RW, Lecapitaine N et al. 2007 Human cardiac stem cells. PNAS 104 14068-14073. (doi:10.1073/pnas.0706760104)

Bibikova M, Laurent LC, Ren B, Loring JF \& Fan JB 2008 Unraveling epigenetic regulation in embryonic stem cells. Cell Stem Cell 2 123-134. (doi:10.1016/j.stem.2008.01.005)

Bilic J \& Izpisua Belmonte JC 2012 Concise review: induced pluripotent stem cells versus embryonic stem cells: close enough or yet too far apart? Stem Cells 30 33-41. (doi:10.1002/stem.700)

Bjorklund LM, Sanchez-Pernaute R, Chung S, Andersson T, Chen IY, McNaught KS, Brownell AL, Jenkins BG, Wahlestedt C, Kim KS et al. 2002 Embryonic stem cells develop into functional dopaminergic neurons after transplantation in a Parkinson rat model. PNAS 99 2344-2349. (doi:10.1073/pnas.022438099)

Blair K, Wray J \& Smith A 2011 The liberation of embryonic stem cells. PLoS Genetics 7 e1002019. (doi:10.1371/journal.pgen.1002019)

Blanpain C, Lowry WE, Geoghegan A, Polak L \& Fuchs E 2004 Selfrenewal, multipotency, and the existence of two cell populations within an epithelial stem cell niche. Cell 118 635-648. (doi:10.1016/ j.cell.2004.08.012)

Blasco MA, Serrano M \& Fernandez-Capetillo O 2011 Genomic instability in iPS: time for a break. EMBO Journal 30 991-993. (doi:10.1038/emboj.2011.50)

Bock C, Kiskinis E, Verstappen G, Gu H, Boulting G, Smith ZD, Ziller M, Croft GF, Amoroso MW, Oakley DH et al. 2011 Reference maps of human ES and iPS cell variation enable high-throughput characterization of pluripotent cell lines. Cell 144 439-452. (doi:10.1016/j.cell.2010.12.032)

Bolli R, Chugh AR, D'Amario D, Loughran JH, Stoddard MF, Ikram S, Beache GM, Wagner SG, Leri A, Hosoda T et al. 2011 Cardiac stem cells in patients with ischaemic cardiomyopathy (SCIPIO): initial results of a randomised phase 1 trial. Lancet 378 1847-1857. (doi:10.1016/S0140-6736(11)61590-0)

Bonaguidi MA, Wheeler MA, Shapiro JS, Stadel RP, Sun GJ, Ming GL \& Song H 2011 In vivo clonal analysis reveals self-renewing and multipotent adult neural stem cell characteristics. Cell 145 1142-1155. (doi:10.1016/j.cell.2011.05.024)

Borovski T, De Sousa E, Melo F, Vermeulen L \& Medema JP 2011 Cancer stem cell niche: the place to be. Cancer Research 71 634-639. (doi:10.1158/0008-5472.CAN-10-3220)

Boulting GL, Kiskinis E, Croft GF, Amoroso MW, Oakley DH, Wainger BJ, Williams DJ, Kahler DJ, Yamaki M, Davidow L et al. 2011 A functionally characterized test set of human induced pluripotent stem cells. Nature Biotechnology 29 279-286. (doi:10.1038/nbt.1783)

Brons IG, Smithers LE, Trotter MW, Rugg-Gunn P, Sun B, Chuva de Sousa Lopes SM, Howlett SK, Clarkson A, Ahrlund-Richter L, Pedersen RA et al. 2007 Derivation of pluripotent epiblast stem cells from mammalian embryos. Nature 448 191-195. (doi:10.1038/nature05950)

Buehr M, Meek S, Blair K, Yang J, Ure J, Silva J, McLay R, Hall J, Ying QL \& Smith A 2008 Capture of authentic embryonic stem cells from rat blastocysts. Cell 135 1287-1298. (doi:10.1016/j.cell.2008. 12.007)

Burke ZD \& Tosh D 2012 Ontogenesis of hepatic and pancreatic stem cells. Stem Cell Reviews 8 586-596. (doi:10.1007/s12015-012-9350-2)

Carey BW, Markoulaki S, Hanna JH, Faddah DA, Buganim Y, Kim J, Ganz K, Steine EJ, Cassady JP, Creyghton MP et al. 2011 Reprogramming factor stoichiometry influences the epigenetic state and biological properties of induced pluripotent stem cells Cell Stem Cell 9 588-598. (doi:10.1016/j.stem.2011.11.003)

Case-law of the European Court of Justice-JUDGMENT OF THE COURT (Grand Chamber) 18 October 2011 (*) (Directive 98/44/EC - article 6(2) (c) - legal protection of biotechnological inventions - extraction of precursor cells from human embryonic stem cells - patentability - exclusion of 'uses of human embryos for industrial or commercial purposes' - concepts of 'human embryo' and 'use for industrial or commercial purposes'). in case C? $34 / 10$,
REFERENCE for a preliminary ruling under article 267 TFEU from the bundesgerichtshof (Germany), made by decision of 17 December 2009, received at the court on 21 January 2010, in the proceedings oliver brüstle vs. greenpeace e.V.,. In.

Castinetti F, Davis SW, Brue T \& Camper SA 2011 Pituitary stem cell update and potential implications for treating hypopituitarism. Endocrine Reviews 32 453-471. (doi:10.1210/er.2010-0011)

Chamberlain SJ, Chen PF, Ng KY, Bourgois-Rocha F, Lemtiri-Chlieh F, Levine ES \& Lalande M 2010 Induced pluripotent stem cell models of the genomic imprinting disorders Angelman and Prader-Willi syndromes. PNAS 107 17668-17673. (doi:10.1073/pnas.1004487107)

Chambers I \& Tomlinson SR 2009 The transcriptional foundation of pluripotency. Development 136 2311-2322. (doi:10.1242/dev. 024398)

Chambers I, Colby D, Robertson M, Nichols J, Lee S, Tweedie S \& Smith A 2003 Functional expression cloning of nanog, a pluripotency sustaining factor in embryonic stem cells. Cell 113 643-655. (doi:10.1016/S0092-8674(03)00392-1)

Chen J, Gremeaux L, Fu Q, Liekens D, Van Laere S \& Vankelecom H 2009 Pituitary progenitor cells tracked down by side population dissection. Stem Cells 27 1182-1195. (doi:10.1002/stem.51)

Cheshier SH, Morrison SJ, Liao X \& Weissman IL 1999 In vivo proliferation and cell cycle kinetics of long-term self-renewing hematopoietic stem cells. PNAS 96 3120-3125. (doi:10.1073/pnas. 96.6.3120)

Cheung TH, Quach NL, Charville GW, Liu L, Park L, Edalati A, Yoo B, Hoang P \& Rando TA 2012 Maintenance of muscle stem-cell quiescence by microRNA-489. Nature 482 524-528. (doi:10.1038/ nature 10834)

Chou YF, Chen HH, Eijpe M, Yabuuchi A, Chenoweth JG, Tesar P, Lu J, McKay RD \& Geijsen N 2008 The growth factor environment defines distinct pluripotent ground states in novel blastocystderived stem cells. Cell 135 449-461. (doi:10.1016/j.cell.2008. 08.035)

Claudinot S, Nicolas M, Oshima H, Rochat A \& Barrandon Y 2005 Long-term renewal of hair follicles from clonogenic multipotent stem cells. PNAS 102 14677-14682. (doi:10.1073/pnas. 0507250102)

Clayton E, Doupe DP, Klein AM, Winton DJ, Simons BD \& Jones PH 2007 A single type of progenitor cell maintains normal epidermis. Nature 446 185-189. (doi:10.1038/nature05574)

Corcione A, Benvenuto F, Ferretti E, Giunti D, Cappiello V, Cazzanti F, Risso M, Gualandi F, Mancardi GL, Pistoia V et al. 2006 Human mesenchymal stem cells modulate B-cell functions. Blood 107 367-372. (doi:10.1182/blood-2005-07-2657)

Costoya JA, Hobbs RM, Barna M, Cattoretti G, Manova K, Sukhwani M, Orwig KE, Wolgemuth DJ \& Pandolfi PP 2004 Essential role of Plzf in maintenance of spermatogonial stem cells. Nature Genetics $\mathbf{3 6}$ 653-659. (doi:10.1038/ng1367)

Cowan CA, Klimanskaya I, McMahon J, Atienza J, Witmyer J, Zucker JP, Wang S, Morton CC, McMahon AP, Powers D et al. 2004 Derivation of embryonic stem-cell lines from human blastocysts. New England Journal of Medicine 350 1353-1356. (doi:10.1056/ NEJMsr040330)

Cyranoski D 2012 The darker side of stem cells. Nature 4835 . (doi:10.1038/483005a)

D'Amario D, Fiorini C, Campbell PM, Goichberg P, Sanada F, Zheng H, Hosoda T, Rota M, Connell JM, Gallegos RP et al. 2011 Functionally competent cardiac stem cells can be isolated from endomyocardial biopsies of patients with advanced cardiomyopathies. Circulation Research 108 857-861. (doi:10.1161/CIRCRESAHA. 111.241380)

DeWitt N 2007 Hwang's clone was really a partenote, daley's report. In The Niche: Stem Cells Blog.

Di Stasi A, Tey SK, Dotti G, Fujita Y, Kennedy-Nasser A, Martinez C, Straathof K, Liu E, Durett AG, Grilley B et al. 2011 Inducible apoptosis as a safety switch for adoptive cell therapy. New England Journal of Medicine 365 1673-1683. (doi:10.1056/NEJMoa1106152) 
Duffy MM, Pindjakova J, Hanley SA, McCarthy C, Weidhofer GA, Sweeney EM, English K, Shaw G, Murphy JM, Barry FP et al. 2011 Mesenchymal stem cell inhibition of T-helper 17 celldifferentiation is triggered by cell-cell contact and mediated by prostaglandin $\mathrm{E}^{2}$ via the EP4 receptor. European Journal of Immunology 41 2840-2851. (doi:10.1002/eji.201141499)

Ellis P, Fagan BM, Magness ST, Hutton S, Taranova O, Hayashi S, McMahon A, Rao M \& Pevny L 2004 SOX2, a persistent marker for multipotential neural stem cells derived from embryonic stem cells, the embryo or the adult. Developmental Neuroscience 26 148-165. (doi:10.1159/000082134)

English K, Barry FP \& Mahon BP 2008 Murine mesenchymal stem cells suppress dendritic cell migration, maturation and antigen presentation. Immunology Letters 115 50-58. (doi:10.1016/j.imlet. 2007.10.002)

Erdo F, Buhrle C, Blunk J, Hoehn M, Xia Y, Fleischmann B, Focking M, Kustermann E, Kolossov E, Hescheler J et al. 2003 Host-dependent tumorigenesis of embryonic stem cell transplantation in experimental stroke. Journal of Cerebral Blood Flow and Metabolism 23 780-785. (doi:10.1097/01.WCB.0000071886.63724.FB)

Evans MJ \& Kaufman MH 1981 Establishment in culture of pluripotential cells from mouse embryos. Nature 292 154-156. (doi:10.1038/292154a0)

Fauquier T, Rizzoti K, Dattani M, Lovell-Badge R \& Robinson IC 2008 SOX2-expressing progenitor cells generate all of the major cell types in the adult mouse pituitary gland. PNAS 105 2907-2912. (doi:10.1073/pnas.0707886105)

Formeister EJ, Sionas AL, Lorance DK, Barkley CL, Lee GH \& Magness ST 2009 Distinct SOX9 levels differentially mark stem/progenitor populations and enteroendocrine cells of the small intestine epithelium. American Journal of Physiology. Gastrointestinal and Liver Physiology 296 G1108-G1118. (doi:10.1152/ajpgi. 00004.2009)

Fuchs E \& Horsley V 2011 Ferreting out stem cells from their niches. Nature Cell Biology 13 513-518. (doi:10.1038/ncb0511-513)

Fugazzola L, Cirello V \& Beck-Peccoz P 2011 Fetal microchimerism as an explanation of disease. Nature Reviews. Endocrinology 7 89-97. (doi:10.1038/nrendo.2010.216)

Galofre JC \& Davis TF 2007 Microchimerism in thyroid disease. Hot Thyroidology 2.

Garcia-Castro J, Alemany R, Cascallo M, Martinez-Quintanilla J, Arriero Mdel M, Lassaletta A, Madero L \& Ramirez M 2010 Treatment of metastatic neuroblastoma with systemic oncolytic virotherapy delivered by autologous mesenchymal stem cells: an exploratory study. Cancer Gene Therapy 17 476-483. (doi:10.1038/ cgt.2010.4)

Garcia-Lavandeira M, Quereda V, Flores I, Saez C, Diaz-Rodriguez E, Japon MA, Ryan AK, Blasco MA, Dieguez C, Malumbres M et al. 2009 A GRFa2/Prop1/stem (GPS) cell niche in the pituitary. PLoS ONE 4 e4815. (doi:10.1371/journal.pone.0004815)

Garcia-Lavandeira M, Diaz-Rodriguez E, Garcia-Rendueles ME, Rodrigues JS, Perez-Romero S, Bravo SB \& Alvarez CV 2010 Functional role of the RET dependence receptor, GFRa co-receptors and ligands in the pituitary. Frontiers of Hormone Research 38 127-138.

Garcia-Lavandeira M, Saez C, Diaz-Rodriguez E, Perez-Romero S, Senra A, Dieguez C, Japon MA \& Alvarez CV 2012 Craniopharyngiomas express embryonic stem cell markers (SOX2, OCT4, KLF4, and SOX9) as pituitary stem cells but do not coexpress RET/GFRA3 receptors. Journal of Clinical Endocrinology and Metabolism 97 E80-E87. (doi:10.1210/jc.2011-2187)

Garcia-Olmo D, Garcia-Arranz M, Herreros D, Pascual I, Peiro C \& Rodriguez-Montes JA 2005 A phase I clinical trial of the treatment of Crohn's fistula by adipose mesenchymal stem cell transplantation. Diseases of the Colon and Rectum 48 1416-1423. (doi:10.1007/s10350-005-0052-6)

Gaston-Massuet C, Andoniadou CL, Signore M, Jayakody SA, Charolidi N, Kyeyune R, Vernay B, Jacques TS, Taketo MM,
Le Tissier $\mathrm{P}$ et al. 2011 Increased wingless (wnt) signaling in pituitary progenitor/stem cells gives rise to pituitary tumors in mice and humans. PNAS 108 11482-11487. (doi:10.1073/pnas. 1101553108)

Ghannam S, Pene J, Torcy-Moquet G, Jorgensen C \& Yssel H 2010 Mesenchymal stem cells inhibit human Th17 cell differentiation and function and induce a T regulatory cell phenotype. Journal of Immunology 185 302-312. (doi:10.4049/jimmunol.0902007)

Gilyarov AV 2008 Nestin in central nervous system cells. Neuroscience and Behavioral Physiology 38 165-169. (doi:10.1007/s11055-008-0025-z)

Gore A, Li Z, Fung HL, Young JE, Agarwal S, Antosiewicz-Bourget J, Canto I, Giorgetti A, Israel MA, Kiskinis E et al. 2011 Somatic coding mutations in human induced pluripotent stem cells. Nature $\mathbf{4 7 1}$ 63-67. (doi:10.1038/nature09805)

Greaves MF 2006 Cord blood donor cell leukemia in recipients. Leukemia 20 1633-1634. (doi:10.1038/sj.leu.2404293)

Guenther MG, Frampton GM, Soldner F, Hockemeyer D, Mitalipova M, Jaenisch R \& Young RA 2010 Chromatin structure and gene expression programs of human embryonic and induced pluripotent stem cells. Cell Stem Cell 7 249-257. (doi:10.1016/j.stem. 2010.06.015)

Gutierrez-Fernandez M, Rodriguez-Frutos B, Alvarez-Grech J, Vallejo-Cremades MT, Exposito-Alcaide M, Merino J, Roda JM \& Diez-Tejedor E 2011 Functional recovery after hematic administration of allogenic mesenchymal stem cells in acute ischemic stroke in rats. Neuroscience 175 394-405. (doi:10.1016/j.neuroscience.2010.11.054)

Hanna J, Cheng AW, Saha K, Kim J, Lengner CJ, Soldner F, Cassady JP, Muffat J, Carey BW \& Jaenisch R 2010 Human embryonic stem cells with biological and epigenetic characteristics similar to those of mouse ESCs. PNAS 107 9222-9227. (doi:10.1073/pnas. 1004584107)

Hatano SY, Tada M, Kimura H, Yamaguchi S, Kono T, Nakano T, Suemori H, Nakatsuji N \& Tada T 2005 Pluripotential competence of cells associated with nanog activity. Mechanisms of Development 122 67-79. (doi:10.1016/j.mod.2004.08.008)

Hirabayashi M, Kato M, Sanbo M, Kobayashi T, Hochi S \& Nakauchi H 2010 Rat transgenesis via embryonic stem cells electroporated with the kusabira-orange gene. Molecular Reproduction and Development 77 474. (doi:10.1002/mrd.21181)

Hockemeyer D, Soldner F, Beard C, Gao Q, Mitalipova M, DeKelver RC, Katibah GE, Amora R, Boydston EA, Zeitler B et al. 2009 Efficient targeting of expressed and silent genes in human ESCs and iPSCs using zinc-finger nucleases. Nature Biotechnology 27 851-857. (doi:10.1038/nbt.1562)

Hockemeyer D, Wang H, Kiani S, Lai CS, Gao Q, Cassady JP, Cost GJ, Zhang L, Santiago Y, Miller JC et al. 2011 Genetic engineering of human pluripotent cells using TALE nucleases. Nature Biotechnology 29 731-734. (doi:10.1038/nbt.1927)

Holland AM, Elefanty AG \& Stanley EG 2009 Pancreatic differentiation from pluripotent stem cells: tweaking the system. Cell Research 19 395-396. (doi:10.1038/cr.2009.37)

Hong H, Takahashi K, Ichisaka T, Aoi T, Kanagawa O, Nakagawa M, Okita K \& Yamanaka S 2009 Suppression of induced pluripotent stem cell generation by the p53-p21 pathway. Nature $\mathbf{4 6 0}$ 1132-1135. (doi:10.1038/nature08235)

Hough SR, Clements I, Welch PJ \& Wiederholt KA 2006 Differentiation of mouse embryonic stem cells after RNA interferencemediated silencing of OCT4 and nanog. Stem Cells 24 1467-1475. (doi:10.1634/stemcells.2005-0475)

Hsu YC, Pasolli HA \& Fuchs E 2011 Dynamics between stem cells, niche, and progeny in the hair follicle. Cell 144 92-105. (doi:10.1016/j.cell.2010.11.049)

Hwang WS, Roh SI, Lee BC, Kang SK, Kwon DK, Kim S, Kim SJ, Park SW, Kwon HS, Lee CK et al. 2005 Patient-specific embryonic stem cells derived from human SCNT blastocysts. Science $\mathbf{3 0 8}$ 1777-1783. (doi:10.1126/science.1112286) 
Jiang H, Shukla A, Wang X, Chen WY, Bernstein BE \& Roeder RG 2011 Role for dpy-30 in ES cell-fate specification by regulation of H3K4 methylation within bivalent domains. Cell 144 513-525. (doi:10.1016/j.cell.2011.01.020)

Kajstura J, Rota M, Hall SR, Hosoda T, D'Amario D, Sanada F, Zheng H, Ogorek B, Rondon-Clavo C, Ferreira-Martins J et al. 2011 Evidence for human lung stem cells. New England Journal of Medicine 364 1795-1806. (doi:10.1056/NEJMoa1101324)

Karbanova J, Missol-Kolka E, Fonseca AV, Lorra C, Janich P, Hollerova H, Jaszai J, Ehrmann J, Kolar Z, Liebers C et al. 2008 The stem cell marker CD133 (prominin-1) is expressed in various human glandular epithelia. Journal of Histochemistry and Cytochemistry 56 977-993. (doi:10.1369/jhc.2008.951897)

Katayama Y, Battista M, Kao WM, Hidalgo A, Peired AJ, Thomas SA \& Frenette PS 2006 Signals from the sympathetic nervous system regulate hematopoietic stem cell egress from bone marrow. Cell 124 407-421. (doi:10.1016/j.cell.2005.10.041)

Kawamata M \& Ochiya T 2010 Generation of genetically modified rats from embryonic stem cells. PNAS 107 14223-14228. (doi:10.1073/ pnas.1009582107)

Kelly KF, Ng DY, Jayakumaran G, Wood GA, Koide H \& Doble BW 2011 $\beta$-Catenin enhances oct 4 activity and reinforces pluripotency through a TCF-independent mechanism. Cell Stem Cell 8 214-227. (doi:10.1016/j.stem.2010.12.010)

Kennedy D 2006 Editorial retraction. Science 311 335. (doi:10.1126/ science.1124926)

Kiel MJ, Yilmaz OH, Iwashita T, Yilmaz OH, Terhorst C \& Morrison SJ 2005 SLAM family receptors distinguish hematopoietic stem and progenitor cells and reveal endothelial niches for stem cells. Cell 121 1109-1121. (doi:10.1016/j.cell.2005.05.026)

Kiel MJ, He S, Ashkenazi R, Gentry SN, Teta M, Kushner JA, Jackson TL \& Morrison SJ 2007 Haematopoietic stem cells do not asymmetrically segregate chromosomes or retain BrdU. Nature 449 238-242. (doi:10.1038/nature06115)

Kim AC, Reuter AL, Zubair M, Else T, Serecky K, Bingham NC, Lavery GG, Parker KL \& Hammer GD 2008 Targeted disruption of $\beta$-catenin in Sf1-expressing cells impairs development and maintenance of the adrenal cortex. Development 135 2593-2602. (doi:10.1242/dev.021493)

Kim J, Su SC, Wang H, Cheng AW, Cassady JP, Lodato MA, Lengner CJ, Chung CY, Dawlaty MM, Tsai LH et al. 2011 Functional integration of dopaminergic neurons directly converted from mouse fibroblasts. Cell Stem Cell 9 413-419. (doi:10.1016/j.stem.2011.09.011)

Klein AM, Nakagawa T, Ichikawa R, Yoshida S \& Simons BD 2010 Mouse germ line stem cells undergo rapid and stochastic turnover. Cell Stem Cell 7 214-224. (doi:10.1016/j.stem.2010.05.017)

Klonisch T \& Drouin R 2009 Fetal-maternal exchange of multipotent stem/progenitor cells: microchimerism in diagnosis and disease. Trends in Molecular Medicine 15 510-518. (doi:10.1016/j.molmed. 2009.09.002)

Kopp JL, Ormsbee BD, Desler M \& Rizzino A 2008 Small increases in the level of Sox2 trigger the differentiation of mouse embryonic stem cells. Stem Cells 26 903-911. (doi:10.1634/stemcells.2007-0951)

Kriegstein A \& Alvarez-Buylla A 2009 The glial nature of embryonic and adult neural stem cells. Annual Review of Neuroscience 32 149-184. (doi:10.1146/annurev.neuro.051508.135600)

Lee J, Kanatsu-Shinohara M, Inoue K, Ogonuki N, Miki H, Toyokuni S, Kimura T, Nakano T, Ogura A \& Shinohara T 2007 Akt mediates self-renewal division of mouse spermatogonial stem cells. Development 134 1853-1859. (doi:10.1242/dev.003004)

Li P, Tong C, Mehrian-Shai R, Jia L, Wu N, Yan Y, Maxson RE, Schulze EN, Song H, Hsieh CL et al. 2008 Germline competent embryonic stem cells derived from rat blastocysts. Cell 135 1299-1310. (doi:10.1016/j.cell.2008.12.006)

Liu L \& Rando TA 2011 Manifestations and mechanisms of stem cell aging. Journal of Cell Biology 193 257-266. (doi:10.1083/jcb. 201010131)
Liu L, Luo GZ, Yang W, Zhao X, Zheng Q, Lv Z, Li W, Wu HJ, Wang L, Wang XJ et al. 2010 Activation of the imprinted Dlk1-Dio3 region correlates with pluripotency levels of mouse stem cells. Journal of Biological Chemistry 285 19483-19490. (doi:10.1074/jbc.M110. 131995)

Liu Y, Wang L, Kikuiri T, Akiyama K, Chen C, Xu X, Yang R, Chen W, Wang S \& Shi S 2011 Mesenchymal stem cell-based tissue regeneration is governed by recipient $\mathrm{T}$ lymphocytes via IFN- $\gamma$ and TNF- $\alpha$. Nature Medicine 17 1594-1601. (doi:10.1038/nm.2542)

Lucas D, Battista M, Shi PA, Isola L \& Frenette PS 2008 Mobilized hematopoietic stem cell yield depends on species-specific circadian timing. Cell Stem Cell 3 364-366. (doi:10.1016/j.stem.2008.09.004)

Lumelsky N, Blondel O, Laeng P, Velasco I, Ravin R \& McKay R 2001 Differentiation of embryonic stem cells to insulin-secreting structures similar to pancreatic islets. Science 292 1389-1394. (doi:10.1126/science.1058866)

Lyashenko N, Winter M, Migliorini D, Biechele T, Moon RT \& Hartmann C 2011 Differential requirement for the dual functions of $\beta$-catenin in embryonic stem cell self-renewal and germ layer formation. Nature Cell Biology 13 753-761. (doi:10.1038/ncb2260)

Marion RM, Strati K, Li H, Tejera A, Schoeftner S, Ortega S, Serrano M \& Blasco MA 2009a Telomeres acquire embryonic stem cell characteristics in induced pluripotent stem cells. Cell Stem Cell 4 141-154. (doi:10.1016/j.stem.2008.12.010)

Marion RM, Strati K, Li H, Murga M, Blanco R, Ortega S, Fernandez-Capetillo O, Serrano M \& Blasco MA $2009 b$ A p53-mediated DNA damage response limits reprogramming to ensure iPS cell genomic integrity. Nature 460 1149-1153. (doi:10.1038/nature08287)

Martin GR 1981 Isolation of a pluripotent cell line from early mouse embryos cultured in medium conditioned by teratocarcinoma stem cells. PNAS 78 7634-7638. (doi:10.1073/pnas.78.12.7634)

Mazumdar J, O'Brien WT, Johnson RS, LaManna JC, Chavez JC, Klein PS \& Simon MC $2010 \mathrm{O}^{2}$ regulates stem cells through Wnt/ $\beta$-catenin signalling. Nature Cell Biology 12 1007-1013. (doi:10.1038/ncb2102)

McMahon MA, Rahdar M \& Porteus M 2011 Gene editing: not just for translation anymore. Nature Methods 9 28-31. (doi:10.1038/ nmeth.1811)

Mendez-Ferrer S, Lucas D, Battista M \& Frenette PS 2008 Haematopoietic stem cell release is regulated by circadian oscillations. Nature 452 442-447. (doi:10.1038/nature06685)

Mendez-Ferrer S, Michurina TV, Ferraro F, Mazloom AR, Macarthur BD, Lira SA, Scadden DT, Ma'ayan A, Enikolopov GN \& Frenette PS 2010 Mesenchymal and haematopoietic stem cells form a unique bone marrow niche. Nature 466 829-834. (doi:10.1038/nature09262)

Meng X, Lindahl M, Hyvonen ME, Parvinen M, de Rooij DG, Hess MW, Raatikainen-Ahokas A, Sainio K, Rauvala H, Lakso M et al. 2000 Regulation of cell fate decision of undifferentiated spermatogonia by GDNF. Science 287 1489-1493. (doi:10.1126/ science.287.5457.1489)

Merkle FT, Mirzadeh Z \& Alvarez-Buylla A 2007 Mosaic organization of neural stem cells in the adult brain. Science 317 381-384. (doi:10.1126/science.1144914)

Mitsui K, Tokuzawa Y, Itoh H, Segawa K, Murakami M, Takahashi K, Maruyama M, Maeda M \& Yamanaka S 2003 The homeoprotein nanog is required for maintenance of pluripotency in mouse epiblast and ES cells. Cell 113 631-642. (doi:10.1016/S00928674(03)00393-3)

Miyabayashi T, Teo JL, Yamamoto M, McMillan M, Nguyen C \& Kahn M 2007 Wnt/ $\beta$-catenin/CBP signaling maintains long-term murine embryonic stem cell pluripotency. PNAS 104 5668-5673. (doi:10.1073/pnas.0701331104)

Miyanari Y \& Torres-Padilla ME 2012 Control of ground-state pluripotency by allelic regulation of nanog. Nature 483 470-473. (doi:10.1038/nature10807)

Moretti A, Bellin M, Welling A, Jung CB, Lam JT, Bott-Flugel L, Dorn T, Goedel A, Hohnke C, Hofmann F et al. 2010 Patient-specific 
induced pluripotent stem-cell models for long-QT syndrome. New England Journal of Medicine 363 1397-1409. (doi:10.1056/ NEJMoa0908679)

Ng HH \& Surani MA 2011 The transcriptional and signalling networks of pluripotency. Nature Cell Biology 13 490-496. (doi:10.1038/ ncb0511-490)

Niwa H \& Fujimori T 2010 Stem cell systems in development of mammals. Development, Growth $\mathcal{E}$ Differentiation 52251. (doi:10.1111/j.1440-169X.2010.01181.x)

Niwa H, Burdon T, Chambers I \& Smith A 1998 Self-renewal of pluripotent embryonic stem cells is mediated via activation of STAT3. Genes and Development 12 2048-2060. (doi:10.1101/gad.12. 13.2048)

Niwa H, Miyazaki J \& Smith AG 2000 Quantitative expression of oct-3/4 defines differentiation, dedifferentiation or self-renewal of ES cells. Nature Genetics 24 372-376. (doi:10.1038/74199)

Oatley JM, Avarbock MR \& Brinster RL 2007 Glial cell line-derived neurotrophic factor regulation of genes essential for self-renewal of mouse spermatogonial stem cells is dependent on src family kinase signaling. Journal of Biological Chemistry 282 25842-25851. (doi:10.1074/jbc.M703474200)

O'Donoghue K 2006 Implications of fetal stem cell trafficking in pregnancy. Reviews in Gynaecological and Perinatal Practice 6 87-98. (doi:10.1016/j.rigapp.2005.11.001)

Ohi Y, Qin H, Hong C, Blouin L, Polo JM, Guo T, Qi Z, Downey SL, Manos PD, Rossi DJ et al. 2011 Incomplete DNA methylation underlies a transcriptional memory of somatic cells in human iPS cells. Nature Cell Biology 13 541-549. (doi:10.1038/ncb2239)

Ohm JE, Mali P, Van Neste L, Berman DM, Liang L, Pandiyan K, Briggs KJ, Zhang W, Argani P, Simons B et al. 2010 Cancer-related epigenome changes associated with reprogramming to induced pluripotent stem cells. Cancer Research 70 7662-7673. (doi:10.1158/0008-5472.CAN-10-1361)

Okita K, Ichisaka T \& Yamanaka S 2007 Generation of germlinecompetent induced pluripotent stem cells. Nature 448 313-317. (doi:10.1038/nature05934)

Okita K, Nakagawa M, Hyenjong H, Ichisaka T \& Yamanaka S 2008 Generation of mouse induced pluripotent stem cells without viral vectors. Science 322 949-953. (doi:10.1126/science.1164270)

Okita K, Matsumura Y, Sato Y, Okada A, Morizane A, Okamoto S, Hong H, Nakagawa M, Tanabe K, Tezuka K et al. 2011 A more efficient method to generate integration-free human iPS cells. Nature Methods 8 409-412. (doi:10.1038/nmeth.1591)

Olson LE, Tollkuhn J, Scafoglio C, Krones A, Zhang J, Ohgi KA, Wu W, Taketo MM, Kemler R, Grosschedl R et al. 2006 Homeodomain-mediated $\beta$-catenin-dependent switching events dictate cell-lineage determination. Cell 125 593-605. (doi:10.1016/j.cell.2006.02.046)

Peljto M, Dasen JS, Mazzoni EO, Jessell TM \& Wichterle H 2010 Functional diversity of ESC-derived motor neuron subtypes revealed through intraspinal transplantation. Cell Stem Cell 7 355-366. (doi:10.1016/j.stem.2010.07.013)

Pera MF \& Tam PP 2010 Extrinsic regulation of pluripotent stem cells. Nature 465 713-720. (doi:10.1038/nature09228)

Peterson SE, Tran HT, Garitaonandia I, Han S, Nickey KS, Leonardo T, Laurent LC \& Loring JF 2011 Teratoma generation in the testis capsule. Journal of Visualized Experiments $\mathbf{5 7}$ e3177.

Rada-Iglesias A, Bajpai R, Swigut T, Brugmann SA, Flynn RA \& Wysocka J 2011 A unique chromatin signature uncovers early developmental enhancers in humans. Nature 470 279-283. (doi:10.1038/nature09692)

Ramiya VK, Maraist M, Arfors KE, Schatz DA, Peck AB \& Cornelius JG 2000 Reversal of insulin-dependent diabetes using islets generated in vitro from pancreatic stem cells. Nature Medicine 6 278-282. (doi:10.1038/73128)

Rando TA 2005 The adult muscle stem cell comes of age. Nature Medicine 11 829-831. (doi:10.1038/nm0805-829)
Relaix F, Rocancourt D, Mansouri A \& Buckingham M 2005 A Pax3/Pax7-dependent population of skeletal muscle progenitor cells. Nature 435 948-953. (doi:10.1038/nature03594)

Reubinoff BE, Pera MF, Fong CY, Trounson A \& Bongso A 2000 Embryonic stem cell lines from human blastocysts: somatic differentiation in vitro. Nature Biotechnology 18 399-404. (doi:10.1038/74447)

da Rocha ST, Edwards CA, Ito M, Ogata T \& Ferguson-Smith AC 2008 Genomic imprinting at the mammalian Dlk1-Dio3 domain. Trends in Genetics 24 306-316. (doi:10.1016/j.tig.2008.03.011)

Rock JR, Onaitis MW, Rawlins EL, Lu Y, Clark CP, Xue Y, Randell SH \& Hogan BL 2009 Basal cells as stem cells of the mouse trachea and human airway epithelium. PNAS 106 12771-12775. (doi:10.1073/ pnas.0906850106)

Saha K, Mei Y, Reisterer CM, Pyzocha NK, Yang J, Muffat J, Davies MC, Alexander MR, Langer R, Anderson DG et al. 2011 Surfaceengineered substrates for improved human pluripotent stem cell culture under fully defined conditions. PNAS 108 18714-18719. (doi:10.1073/pnas.1114854108)

Saito T, Kuang JQ, Bittira B, Al-Khaldi A \& Chiu RC 2002 Xenotransplant cardiac chimera: immune tolerance of adult stem cells. Annals of Thoracic Surgery 74 19-24 (discussion 24). (doi:10.1016/S0003-4975(02)03591-9)

Sakai K, Yamamoto A, Matsubara K, Nakamura S, Naruse M, Yamagata M, Sakamoto K, Tauchi R, Wakao N, Imagama S et al. 2012 Human dental pulp-derived stem cells promote locomotor recovery after complete transection of the rat spinal cord by multiple neuroregenerative mechanisms. Journal of Clinical Investigation 122 80-90. (doi:10.1172/JCI59251)

Sangiorgi E \& Capecchi MR 2008 Bmil is expressed in vivo in intestinal stem cells. Nature Genetics 40 915-920. (doi:10.1038/ng.165)

Schu S, Nosov M, O'Flynn L, Shaw G, Treacy O, Barry F, Murphy M, O'Brien T \& Ritter T 2012 Immunogenicity of allogeneic mesenchymal stem cells. Journal of Cellular and Molecular Medicine. In press. (doi:10.1111/j.1582-4934.2011.01509.x)

Snippert HJ, van der Flier LG, Sato T, van Es JH, van den Born M, Kroon-Veenboer C, Barker N, Klein AM, van Rheenen J, Simons BD et al. 2010 Intestinal crypt homeostasis results from neutral competition between symmetrically dividing Lgr5 stem cells. Cell 143 134-144. (doi:10.1016/j.cell.2010.09.016)

Snyder EY \& Teng YD 2012 Stem cells and spinal cord repair. New England Journal of Medicine 366 1940-1942. (doi:10.1056/ NEJMcibr1200138)

Soria B, Roche E, Berna G, Leon-Quinto T, Reig JA \& Martin F 2000 Insulin-secreting cells derived from embryonic stem cells normalize glycemia in streptozotocin-induced diabetic mice. Diabetes $\mathbf{4 9}$ 157-162. (doi:10.2337/diabetes.49.2.157)

Spaggiari GM, Capobianco A, Abdelrazik H, Becchetti F, Mingari MC \& Moretta L 2008 Mesenchymal stem cells inhibit natural killer-cell proliferation, cytotoxicity, and cytokine production: role of indoleamine 2,3-dioxygenase and prostaglandin E2. Blood 111 1327-1333. (doi:10.1182/blood-2007-02-074997)

Steinhauser ML, Bailey AP, Senyo SE, Guillermier C, Perlstein TS, Gould AP, Lee RT \& Lechene CP 2012 Multi-isotope imaging mass spectrometry quantifies stem cell division and metabolism. Nature 481 516-519. (doi:10.1038/nature10734)

Stewart CL, Kaspar P, Brunet LJ, Bhatt H, Gadi I, Kontgen F \& Abbondanzo SJ 1992 Blastocyst implantation depends on maternal expression of leukaemia inhibitory factor. Nature 359 76-79. (doi:10.1038/359076a0)

Suga H, Kadoshima T, Minaguchi M, Ohgushi M, Soen M, Nakano T, Takata N, Wataya T, Muguruma K, Miyoshi H et al. 2011 Selfformation of functional adenohypophysis in three-dimensional culture. Nature 480 57-62. (doi:10.1038/nature10637)

Suh H, Consiglio A, Ray J, Sawai T, D’Amour KA \& Gage FH 2007 In vivo fate analysis reveals the multipotent and self-renewal capacities of Sox2+ neural stem cells in the adult hippocampus. Cell Stem Cell 1 515-528. (doi:10.1016/j.stem.2007.09.002) 
Takahashi K \& Yamanaka S 2006 Induction of pluripotent stem cells from mouse embryonic and adult fibroblast cultures by defined factors. Cell 126 663-676. (doi:10.1016/j.cell.2006.07.024)

Takahashi K, Tanabe K, Ohnuki M, Narita M, Ichisaka T, Tomoda K \& Yamanaka S 2007 Induction of pluripotent stem cells from adult human fibroblasts by defined factors. Cell 131 861-872. (doi:10.1016/j.cell.2007.11.019)

Tang F, Barbacioru C, Bao S, Lee C, Nordman E, Wang X, Lao K \& Surani MA 2010 Tracing the derivation of embryonic stem cells from the inner cell mass by single-cell RNA-seq analysis. Cell Stem Cell 6 468-478. (doi:10.1016/j.stem.2010.03.015)

Tesar PJ, Chenoweth JG, Brook FA, Davies TJ, Evans EP, Mack DL, Gardner RL \& McKay RD 2007 New cell lines from mouse epiblast share defining features with human embryonic stem cells. Nature 448 196-199. (doi:10.1038/nature05972)

Thomson JA, Itskovitz-Eldor J, Shapiro SS, Waknitz MA, Swiergiel JJ, Marshall VS \& Jones JM 1998 Embryonic stem cell lines derived from human blastocysts. Science 282 1145-1147. (doi:10.1126/ science.282.5391.1145)

Tumbar T, Guasch G, Greco V, Blanpain C, Lowry WE, Rendl M \& Fuchs E 2004 Defining the epithelial stem cell niche in skin. Science 303 359-363. (doi:10.1126/science.1092436)

Uccelli A, Moretta L \& Pistoia V 2008 Mesenchymal stem cells in health and disease. Nature Reviews. Immunology 8 726-736. (doi:10.1038/ nri2395)

Villeda SA, Luo J, Mosher KI, Zou B, Britschgi M, Bieri G, Stan TM, Fainberg N, Ding Z, Eggel A et al. 2011 The ageing systemic milieu negatively regulates neurogenesis and cognitive function. Nature 477 90-94. (doi:10.1038/nature10357)

Williams RL, Hilton DJ, Pease S, Willson TA, Stewart CL, Gearing DP, Wagner EF, Metcalf D, Nicola NA \& Gough NM 1988 Myeloid leukaemia inhibitory factor maintains the developmental potential of embryonic stem cells. Nature 336 684-687. (doi:10.1038/ $336684 \mathrm{a} 0)$
Wilmut I, Schnieke AE, McWhir J, Kind AJ \& Campbell KH 1997 Viable offspring derived from fetal and adult mammalian cells. Nature 385 810-813. (doi:10.1038/385810a0)

Wray J, Kalkan T, Gomez-Lopez S, Eckardt D, Cook A, Kemler R \& Smith A 2011 Inhibition of glycogen synthase kinase-3 alleviates Tcf3 repression of the pluripotency network and increases embryonic stem cell resistance to differentiation. Nature Cell Biology 13 838-845. (doi:10.1038/ncb2267)

Xu X, D'Hoker J, Stange G, Bonne S, De Leu N, Xiao X, Van de Casteele M, Mellitzer G, Ling Z, Pipeleers D et al. 2008 \& Cells can be generated from endogenous progenitors in injured adult mouse pancreas. Cell 132 197-207. (doi:10.1016/j.cell.2007.12.015)

Ying QL, Wray J, Nichols J, Batlle-Morera L, Doble B, Woodgett J, Cohen P \& Smith A 2008 The ground state of embryonic stem cell self-renewal. Nature 453 519-523. (doi:10.1038/nature06968)

Yu J, Vodyanik MA, Smuga-Otto K, Antosiewicz-Bourget J, Frane JL, Tian S, Nie J, Jonsdottir GA, Ruotti V, Stewart R et al. 2007 Induced pluripotent stem cell lines derived from human somatic cells. Science 318 1917-1920. (doi:10.1126/science.1151526)

Zapata AG 2012 Bone marrow stroma: a source of mesenchymal stem cells for cell therapy. In Stem Cells in Human Reproduction: Basic Science and Therapeutic Potential, 3rd edn. Eds C Simon, A Pellicer \& RA Reijo Pera. New York: Cambridge University Press.

Zhao T, Zhang ZN, Rong Z \& Xu Y 2011 Immunogenicity of induced pluripotent stem cells. Nature 474 212-215. (doi:10.1038/ nature09971)

Zhou H, Wu S, Joo JY, Zhu S, Han DW, Lin T, Trauger S, Bien G, Yao S, Zhu Yet al. 2009 Generation of induced pluripotent stem cells using recombinant proteins. Cell Stem Cell 4 381-384. (doi:10.1016/j.stem. 2009.04.005)

Received in final form 5 July 2012

Accepted 19 July 2012

Made available online as an Accepted Preprint 19 July 2012 